Journal of Educational

and Psychological Sciences

Volume (5), Issue (30): 30 Aug 2021

P: 58 - 76

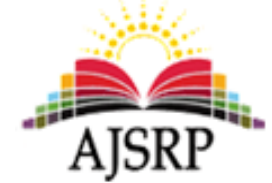

ISSN: 2522-3399

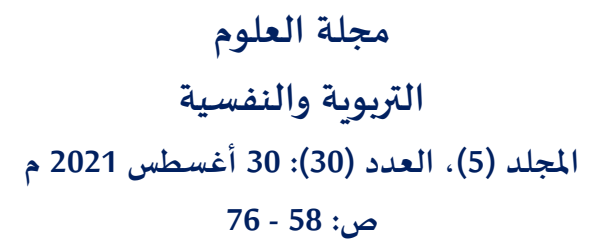

ص: 58 - 76

\title{
The Effect of Artificial Intelligence (Microbit) in Raising the Motivation Towards Learning Programming Among the Students of Educational Technology at King Abdulaziz University in Jeddah
}

\author{
Samaher Ahmed Al-Qarni \\ Amani Mohammed Omran \\ Faculty of Educational Graduate Studies || King Abdulaziz University || KSA
}

\begin{abstract}
The research seeks to know the effect of Artificial Intelligence (Microbit) in raising the motivation towards learning programming among the students of educational technology at King Abdulaziz University in Jeddah. The sample consisted of (14) students, and the research followed the quasi-experimental method for one experimental group. Also, a pre-measurement and post-measurement was done by using the motivation measure towards learning programming. The results of the research confirmed that there were statistically significant differences at the level of significance (0.001) between the results of students for their motivation towards learning programming before and after the use of the (Microbit) in favor of post-measurement. The research also recommended the importance of employing artificial intelligence techniques in curricula and academic projects for its effective role in making the education process active, improving the performance of male and female students and raising their motivation. As well as, preparing educational institutions and centers, and training teachers to work using artificial intelligence techniques, especially the Microbit device.
\end{abstract} Keywords: Motivation, Artificial Intelligence, Microbit.

$$
\begin{aligned}
& \text { أثر الذكاء الاصطناعي المايكروبت (Microbit) في رفع الدافعية نحو تعلُّم البرمجة } \\
& \text { لدى الطالبات في مقرر تقنيات التعليم بجامعة الملك عبد العزيز بجدة } \\
& \text { سماهر أحمد القرني } \\
& \text { أماني محمد عمران } \\
& \text { كلية الدراسات العليا التربوية || جامعة الملك عبد العزيز || المملكة العببية السعودية }
\end{aligned}
$$

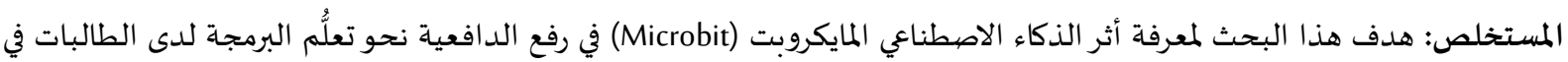

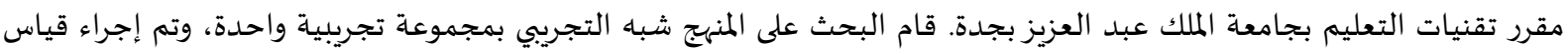

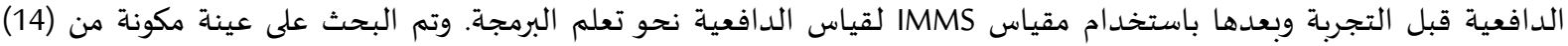

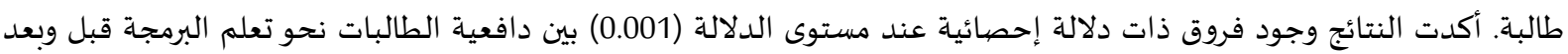

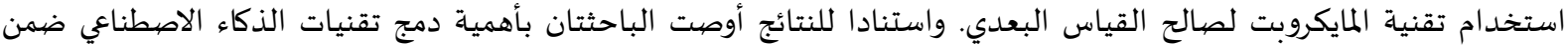

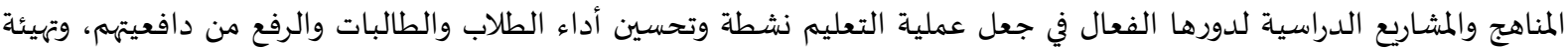
المؤسسات والمراكز التعليمية، وتدريب المعلمين للعمل على تفعيل تقنيات الذكاء الاصطناعي لاسيما جهاز المايكروبت. الكلمات المفتاحية: الدافعية، الذكاء الاصطناعي، المايكروبت، Microbit. 
تتقدم التكنولوجيا يوماً بعد يوم، وتتطور بشكل مستمر ومتعاقب بشكل ملحوظ، وفي ظل هذه التطورات

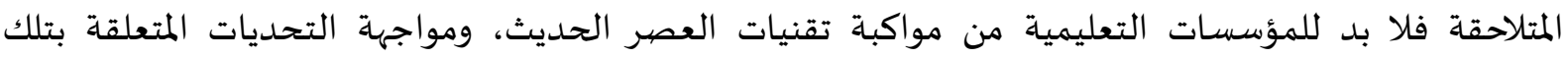
التقنيات لتكون على اطلاع بكل ما هو حديث. فقد تواتر ظهور التقنيات الحديثة بدء من الوسائل السمعية

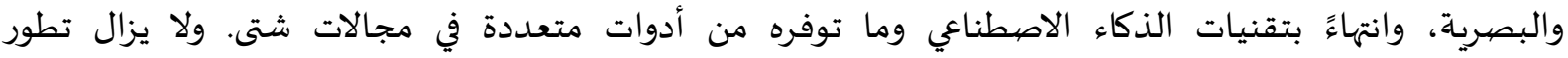

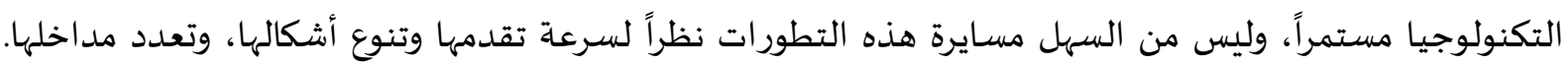

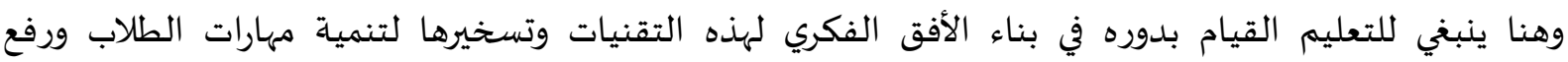
تحصيلهم الدراسي ودافعيتهم نحو التعلم. وتُعد الدافعية للتعلم من أهم مقومات التعليم، والتي ترفع من التحصيل الدراسي للمتعلمين وتمني المهارات المختلفة، وتعزز ثقة الطلاب في أنفسهم وفيما يتعلمونه، وتجعلهم متحمسين ومبادرين في أداء مهامهم التعليمية، كما أن للدافعية أثر في قيام المتعلمين باختيار التحديات الصعبة ومواجهتهم لحالات الفشل وتحويلها إلى تعلم ايجابي (أبو

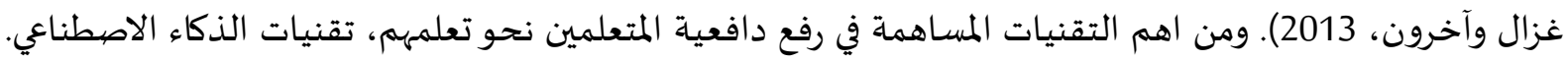

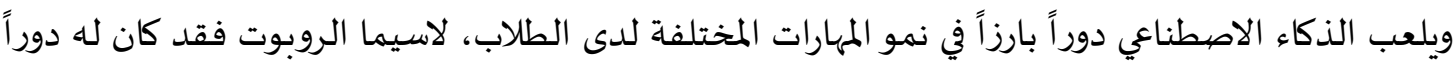
فاعلاً في رفع الدافعية لدى المتعلمين وتنمية مهارات حل المشكلات، وإثارة اهتمامهم للتعلم (Jawawi et.al, 2015). أما البدو (Al Bado, 20117) فقد أثبت في دراسته أن استخدام الذكاء الاصطناعي يساهم في رفع التحصيل الدراسي

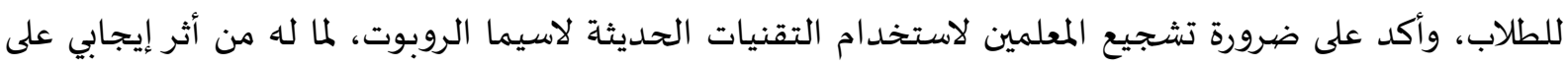

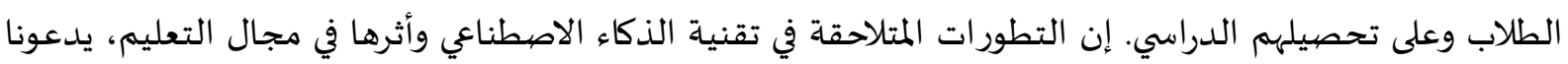
إلى التوجه لتقنيات الذكاء الاصطناعي التي تغير مسار التعلم وتنقلنا إلى عالم آلخر.

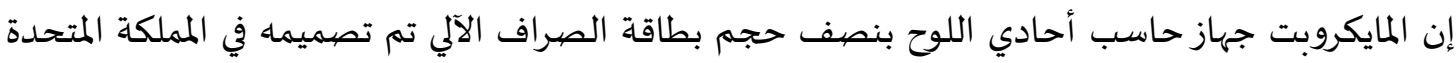
بالتعاون بين (29) شريكا وعلى رأسهم هيئة الإذاعة البريطانية BBC بهدف استخدامه في مجال التهال التعليم، وكان الهدف

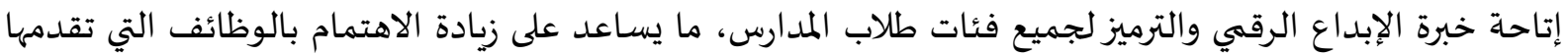

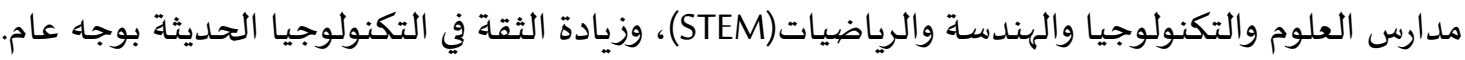
ويتميز المايكروبت بعدة امور منها دعما للغات برمجة مختلفة مثل جافا سكريبت وبايثون، دعماه لمنصات

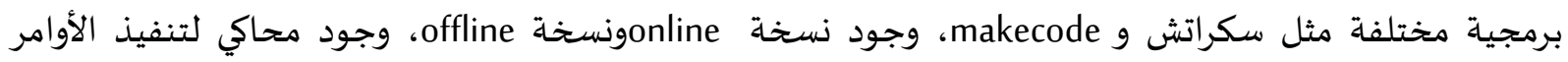

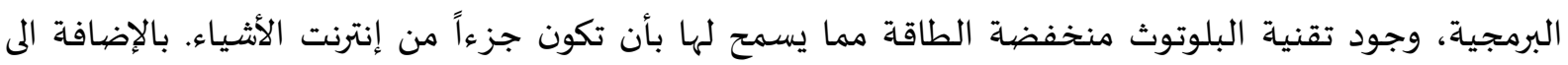

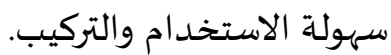
كما أظهرت دراسة هودجزوآخرون (Hodges et al.,2017) نتائج ايجابية حول تجربة التلاميذ من استخدام وماى انخراطهم، تم تحليل تجربة استخدامهم من خلال أربعة مجالات (الدافعية، التعاون، الإبداع

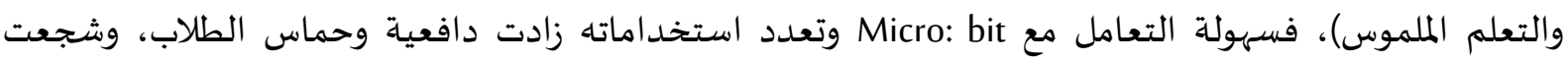

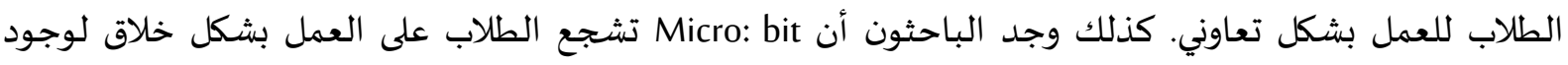
روابط متنوعة لموضوعات STEM مثل (محاكاة السلوك في علم الأحياء، جمع وتحليل القياسات في الفئون الفيزياء،

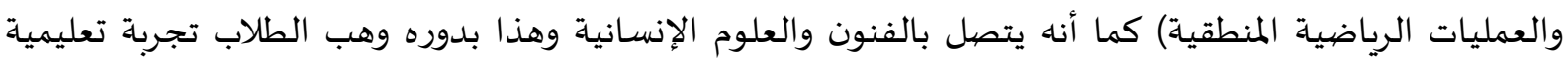

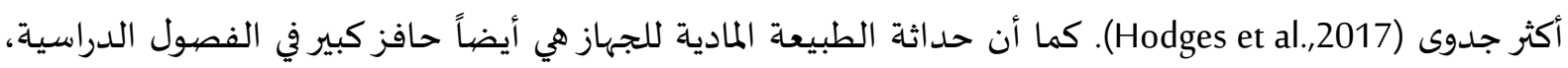
فالتعلم الملموس عنصر رئيسي في تحفيز الاهتمام ودعم الفهم، فأصبح الطلاب يربطون بين تعلم البرمجة وصنع 
المنتجات الرقمية، كل ذلك أثبت أن Micro: bit لدياه القدرة على تحسين التعلم في المجالات الأربعة لدى الطلاب .(Hodges et al.,2017)

في عصر التغيرات المتسارعة ومع التطور الهائل في مجال التعليم تغيرت وظيفة تقنيات التعليم، فتحولت

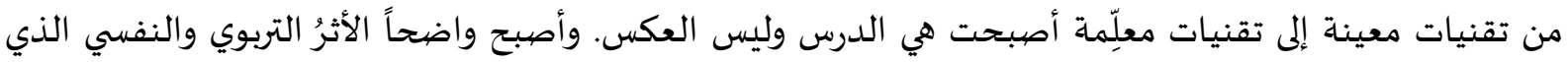

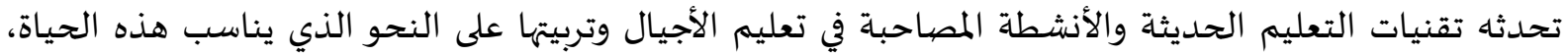

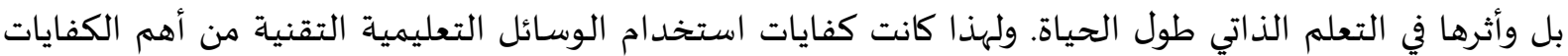
اللازمة للمعلم والمتعلم، للخروج بالمدرسة الحديثة من إطار التخلف والتقليد، من خلال زيادة التفاعل القائم بين المعلم والمتعلم، وزيادة مردود العملية التربوية، وجعلها أكثر فعالية وكفاءة. هذا المساق هو تعريف بالتقنيات الحديثة

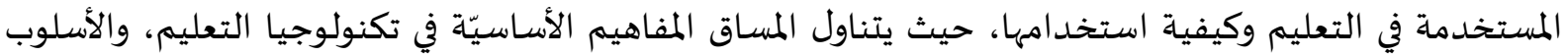
النظامي، وكذلك الإدراك والاتصال وعلاقهما بتكنولوجيا التعليم، والتعلّم الإلكتروني، والتعلّم المبرهج، والتمييز

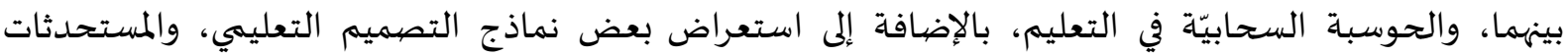

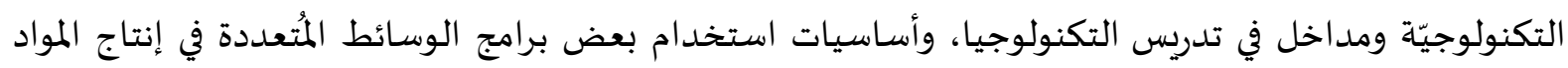

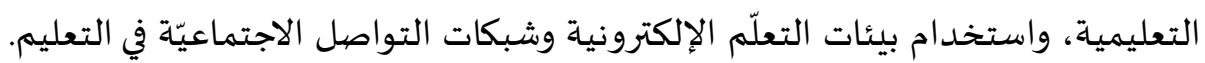

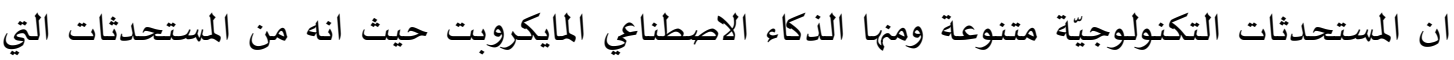

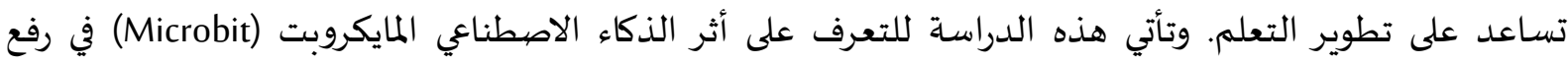

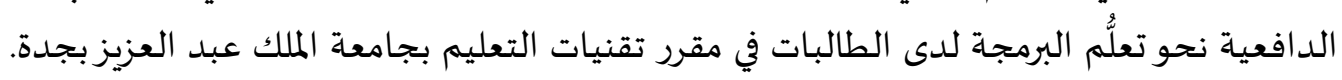

مشكلة البحث:

أكد توباليا وكاجيلتي (Topallia \& Cagiltay, 2018) أنه رغم الاهتمام الذي تحظى به مهارات البرمجة بين

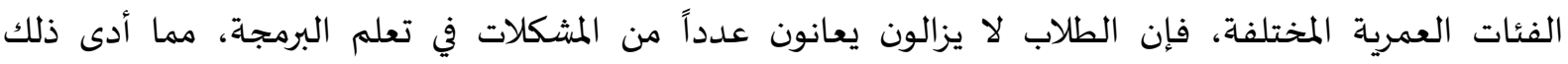
لانخفاض مستويات الدافعية لدى الطلاب. وقد ذكر جنكيس (Jenkins, 2001) بأن هنالك مشكلات تحيط بتعليم البرمجة، ولعل أهمها الدافعية، فقد أظهرت دراسته بعض الأسباب لانخفاض تعلم البرمجاتة من أهمها أن المتعلمين

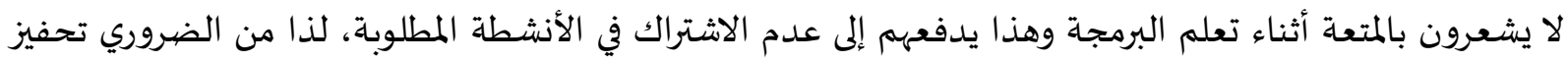

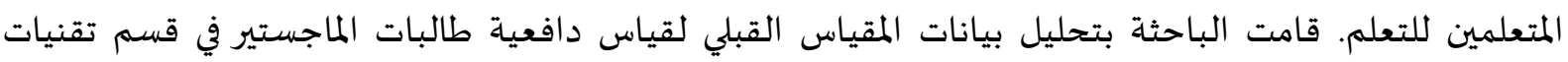
التعليم بجامعة الملك عبد العزيز نحو تعلم البرمجة.

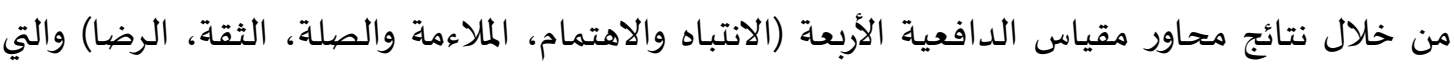
أتت بمتوسط عام (1,78 من 5) وهي تمثل درجة غير موافق بشدة، يتضح لنا مدى انخفاض دافعية الطالبات نحو

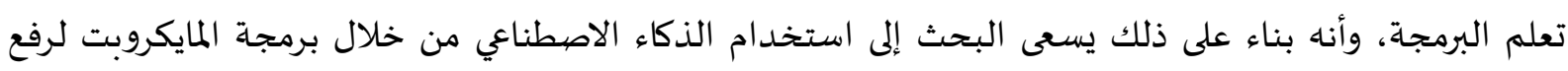

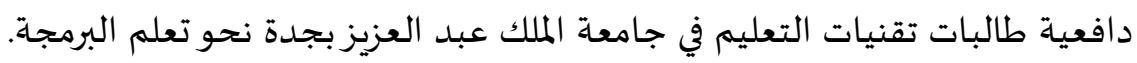

أسئلة البحث

تتحدد مشكلة البحث في السؤال التالي:

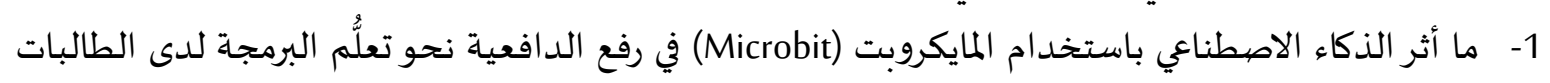

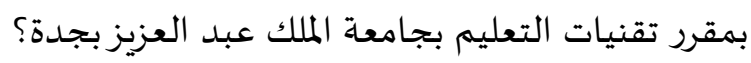


يهدف البحث إلى بيان أثر الذكاء الاصطناعي باستخدام المايكروبت (Microbit) في رفع الدافعية نحو تعلُّم

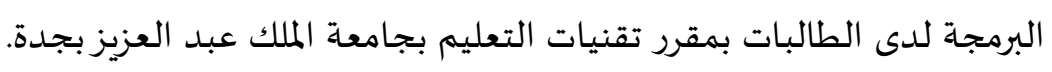

تتمثل أهمية البحث في أنهاه قد يفيد على النحو الآتي:

تبصير القيادات التربوية والمعلمين بآلية جديدة تفيد في رفع الدافعية نحو تعلم البرمجة وليدية وزيادة الخبرات

التعليمية لدى طالبات تقنيات التعليم عن آلية برمجة المايكروبت (Microbit).

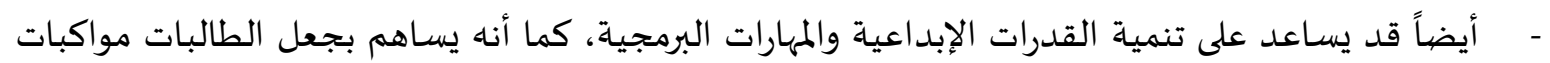

لمستجدات التقنية.

قد يفيد في تزويد المهتمين بمجال المايكروبت بتوصيات قد تثري ذوي الاختصاص في البرمجة والساعيين

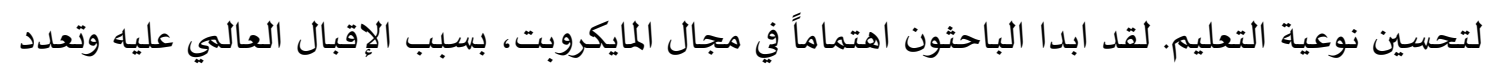
مجالات استخدامه في التعليم. - قد يفيد أيضاً في إثراء المكتبات العربية نظراً لافتقارها لأبحاث ودراسات في مجال المايكروبت.

حدود البحث

اقتصرت الدراسة على الحدود الآتية:

الحدود الموضيوعية: أثر الذكاء الاصطناعي باستخدام المايكروبت (Microbit) في رفع الدافعية نحو تعلُمّ

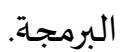

الحدود البشرية: طالبات الماجستير بمقرر تقنيات التعليم.

الحدود المكانية: جامعة الملك عبد العزيزفي مدينة جدة.

الحدود الزمنية: أجريت الدراسة في الفصل الدراسي الثاني لعام 2021/2020 م.

مصطلحات البحث

- الدافعية للتعلم: تُعرفها الرايقي (2018) حالة داخلية للمتعلم تؤجج رغبته للنجاح، وبذل الجهد لتحقيق

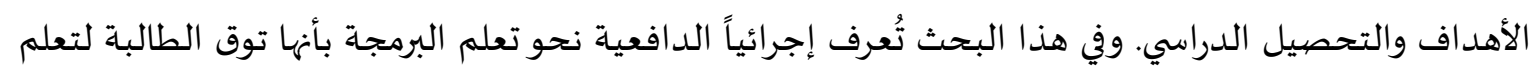

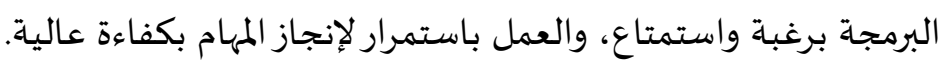

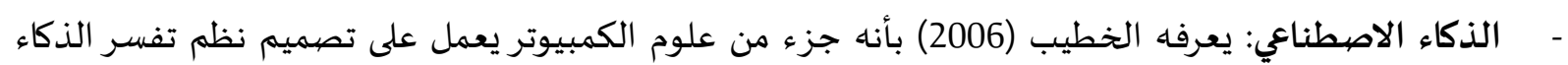

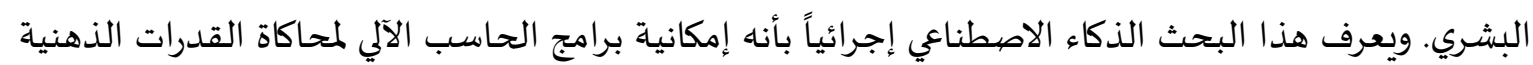

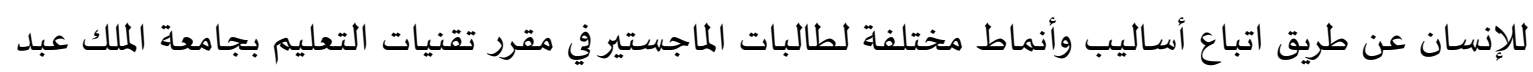

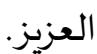
جهاز المايكروبت: كمبيوتر متنقل صغير الحجم ولديه قابلية للبرمجة، ويمكن استخدامه في الابتكارات الشيقة

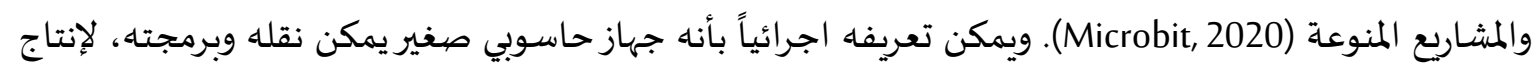

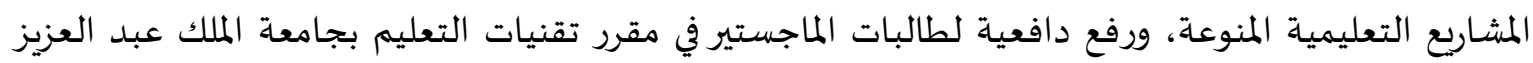
للتعلم من خلاله. 
2- 2 - 2 الإطار النظري والدراسـات السـابقة

أولاً - الإطار النظري.

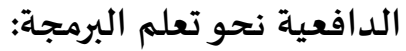

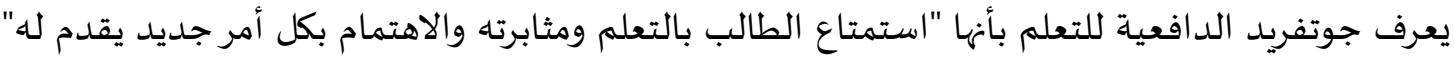
(Gottfried, 1990, 525) فالدافعية تنشط سلوك المتعلم وتحوله من متلقي سلبي إلى متعلم نشط، كما أهنا تقود وتوجه سلوك المتعلم نحو هدف محدد، أيضاً تدعم الدافعية سلوك المتعلم وتسـاعده في تحقيق رغباته والاستمرار لأجل التعلم (العتيبي، 2017). ويمكن زيادة مستوى الدافعية نحو التعلم من خلال عرض مواقف وخبرات تربط تعليم الطلاب بحاجاتهم

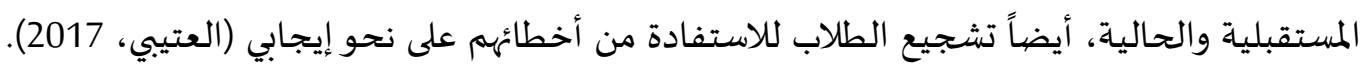
أشار خليلة وآخرون (Khaleel et al., 2019) إلى تدني مستوى الدطابه الدافعية لدى المتعلمين المبتدئين في علوم الكمبيوتر نحو تعلم البرمجة، فهدفت الدراسة إلى رفع الدافعية نحو تعلم البرمجة من خلال موقع تعليمي يقوم على الى استراتيجية التلعيب Gamification. وكشفت النتائج إلى وجود فروق ذاتع ذات دلالة إحصائية في النتائج الكلية لأداء

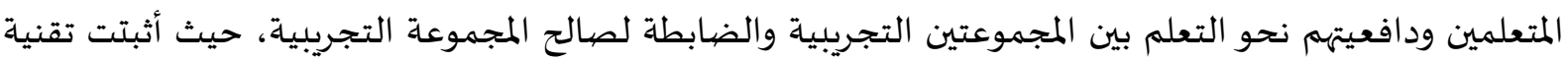
فاعليتها في حل مشاكل تعلم لغة البرمجة وزيادة أداء الطلاب ورفع دافعيتهم (Khaleel et al., 2019). كما أظهرت نتائج دراسة جوميز وآخرون (Gomes et al. 2018) بأن هنالك علاقة إيجابية وارتباط بين أداء الطلاب والدافعية نحو تعلم البرمجة بناءً على نموذج (ARCS)، حيث تعد الدافعية والإدراك الذاتي للكفاءة عاملان أساسيان

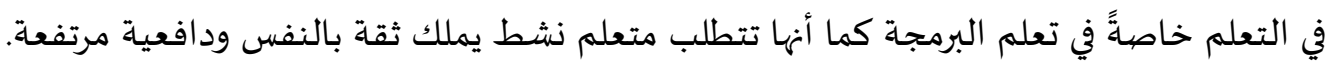

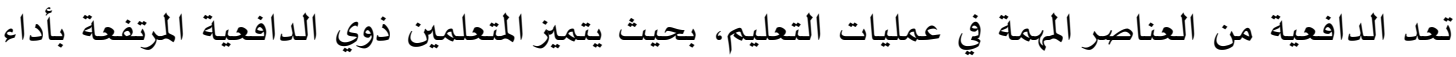

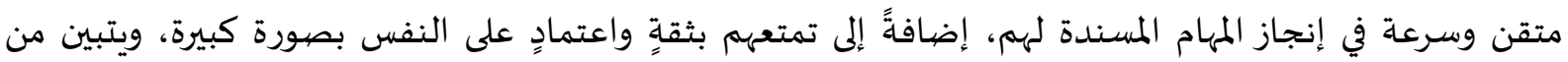

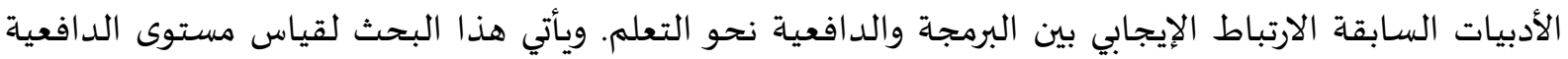

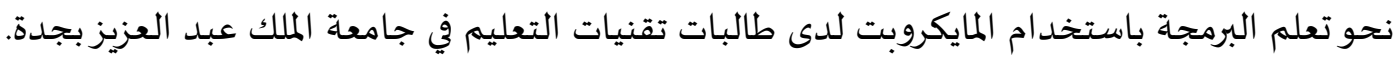

الذكاء الاصطناعي: أعلن عدد من علماء الحاسب ظهور ونشأة الذكاء الاصطناعي لأول مرة بمؤتمر دارتموث (Dartmouth) عام

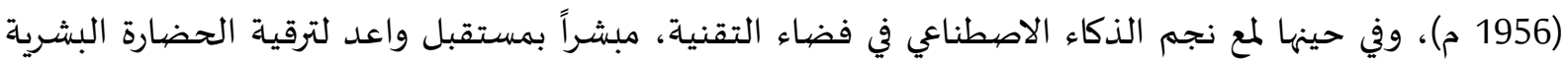
(موسى وبلال، 2019). ويعرف الخطيب (2006) الذكاء الاصطناعي بأنه "جزء من العلوم الحاسوبية التي تهتم

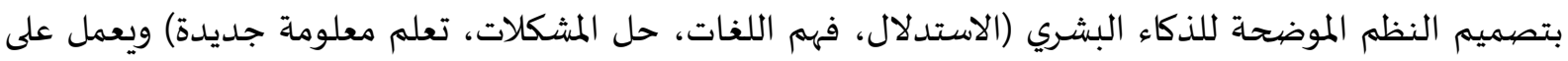

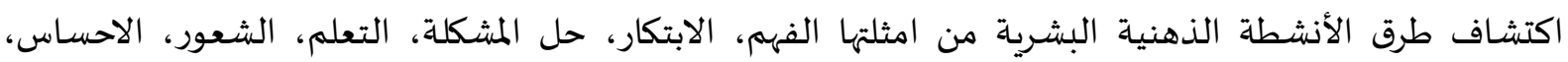

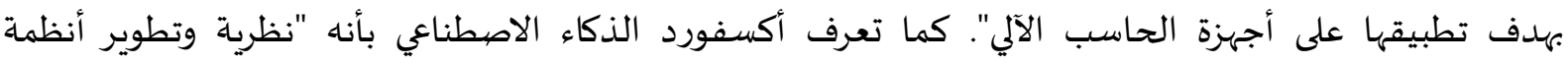

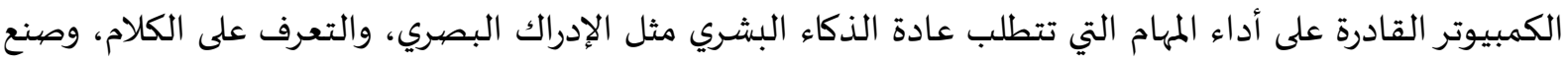

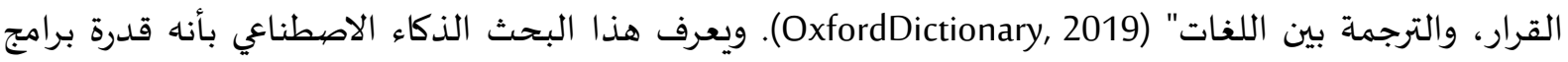
الحاسب الآلي على محاكاة القدرات الذهنية للإنسان عن طريق اتباع أساليب وأنماط مختلفة.

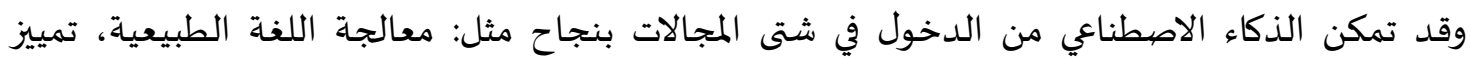

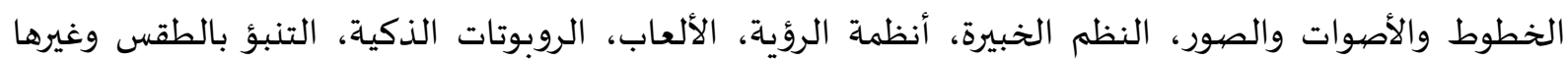




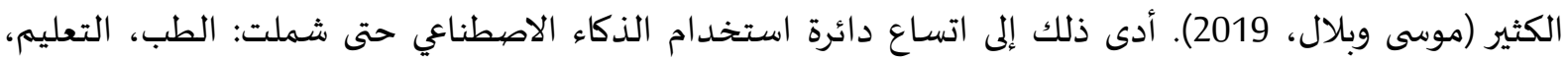

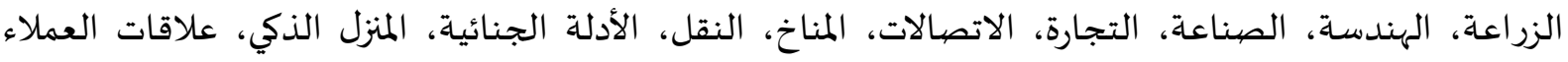

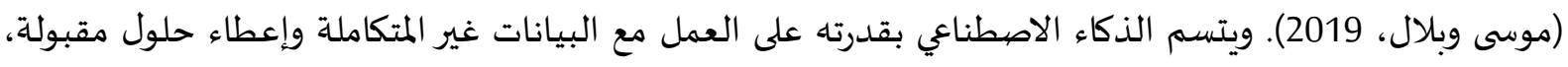

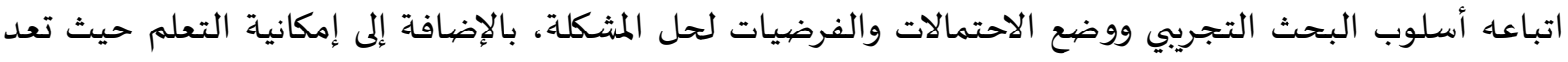

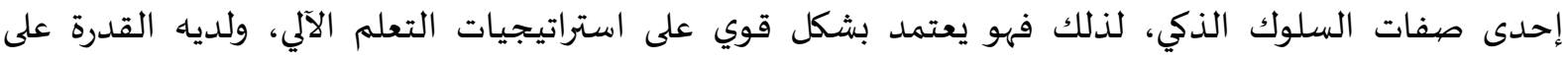
احتضان المعرفة وتمثيلها، فبرامج الذكاء الاصطناعي تبنى على أساس متين من المعرفة للربط بين الحالات والنتائج

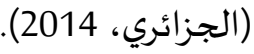

تعريف الذكاء الاصطناعي: تعرف أكسفورد الذكاء الاصطناعي بأنه "نظرية وتطوير أنظمة الكمبيوتر القادرة على أداء المهام التي تقتضي

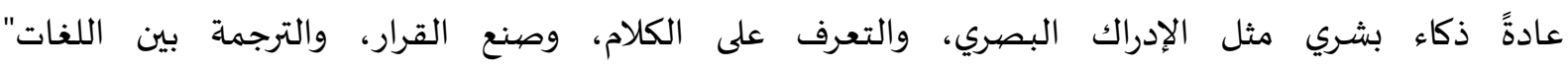

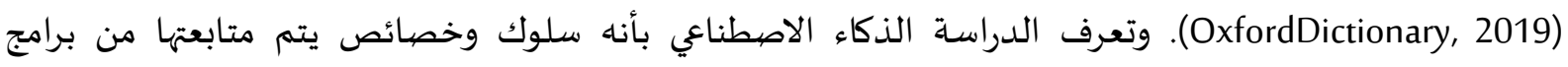
الحاسب الآلي حتى تصبح قادرة على محاكاة القدرات الذهنية للإنسان بأساليب وأنماط مختلفة.

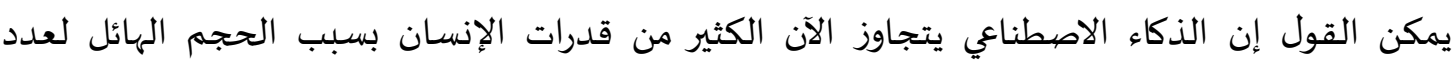

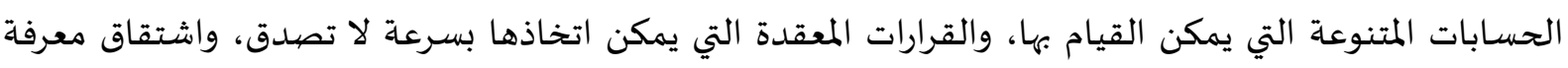

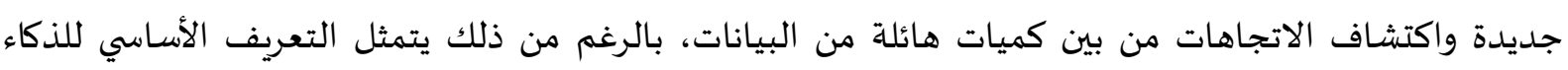
الاصطناعي في تحقيق هدف تقليد السلوك البشري بمهارة (Mohammed, 2019).

مصطلحات مرتبطة بالذكاء الاصطناعي:

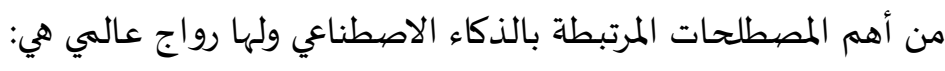

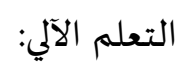

هو التعلم الذي يُعنى بتطوير التقنيات والخوارزميات التي من شأهها تمكين أجهزة الحاسب من التعلم، وتصميم تطبيقات برمجية لها القدرة عل التنبؤ وتوقع النتائج (موسى وبلال، 2019).

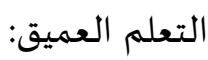
هو امتداد للتعلم الآلي حيث يستند على مجموعات خوارزمية تحتوي على شبكات عصبية اصطناعية تشبها الخلايا العصبية في جسم الإنسان (موسى وبلال، 2019). 


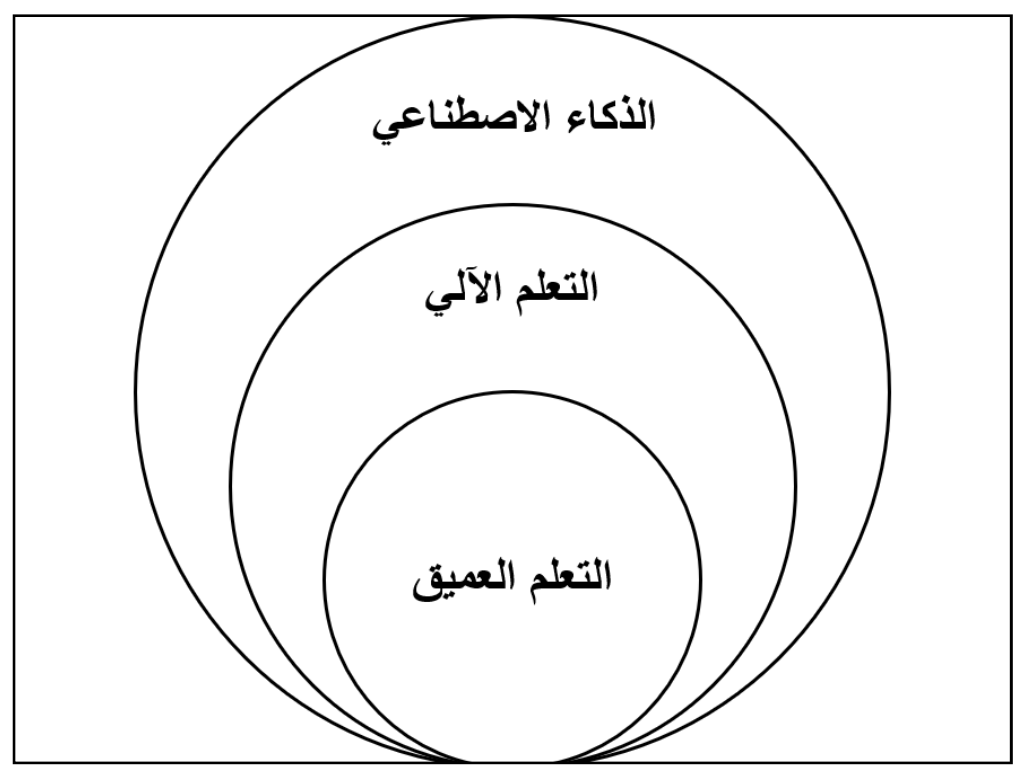

شكل (1): العلاقة بين الذكاء الاصطناعي وأهم مصطلحاته (McClelland, 2017)

$$
\text { أهمية الذكاء الاصطناعي: }
$$

1. يقوم الذكاء الاصطناعي بحفظ الخبرات البشرية المتراكمة ونقلها للآلات الذكية.

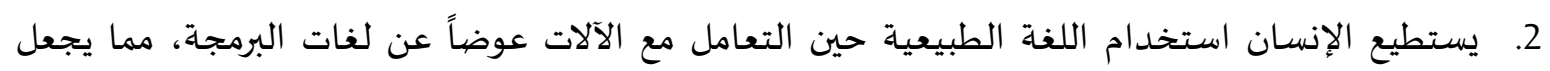

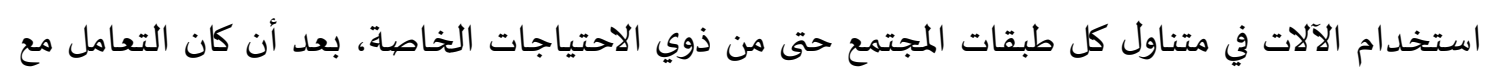

$$
\text { الآلات المتقدمة حكراً على المختصين وأصحاب الآلات في الخبرات. }
$$

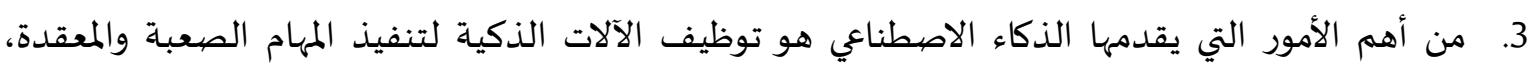

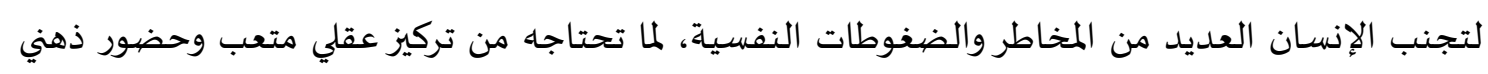
مستمر وقرارات حساسة وسريعة لا تحتمل التأخير أو الخطأ. 4. تساعد أنظمة الذكاء الاصطناعي في مجالات صنع القرار، فهي تتمتع بالاستقلالية والدقة والموضيوعية،

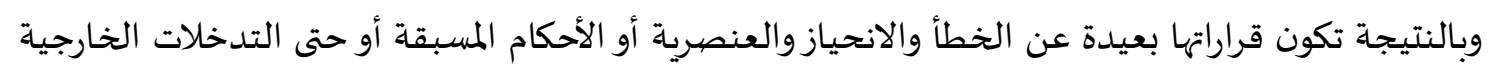
أو الشخصية.

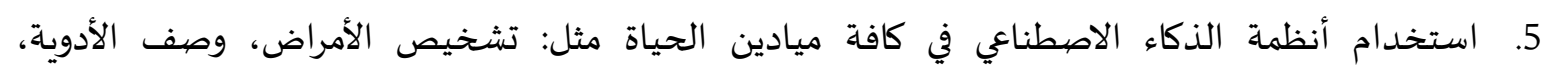

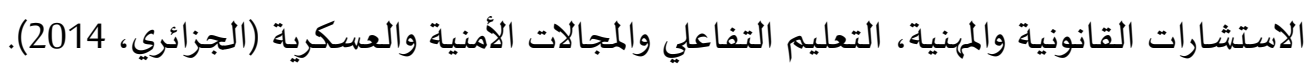

\section{أنواع الذكاء الاصطناعي ومجالاته التطبيقية}

$$
\text { يمكن تصنيف الذكاء الاصطناعي بناءً على القدرات كالتالية الذيطية }
$$

الذكاء الاصطناعي الضيق Weak Al or Narrow Al: وهو النوع القائم على أداء مهمة محددة ضمنمن مجال

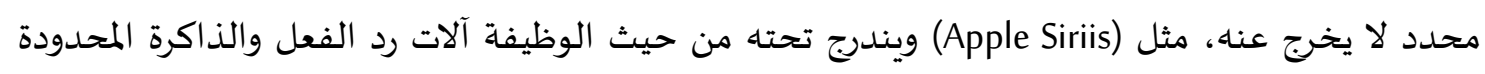

.(Southgate, at.al, 2019) 
الذكاء الاصطناعي العام General Al: كما يطلق عليه الذكاء الاصطناعي القوي، وهو ذكاء اصطناعي يحاكي

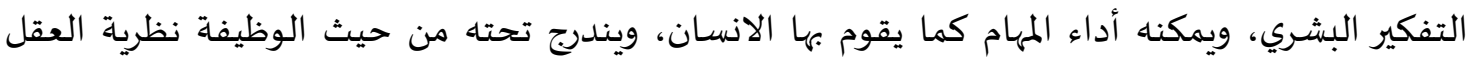
والوعي الذاتي (Southgate, at.al, 2019). الذكاء الاصطناعي الخارق Super Al: وهو مستوى يتجاوز الذكاء البشري، لكنه لايزال مفهوم افتراضي غير مطبق فعلياً (Southgate, at.al, 2019).

لقد هيمن الذكاء الاصطناعي بأنواعه المختلفة على مجالات متعددة، ومن هذه المجالات التطبيقية ما يلي:

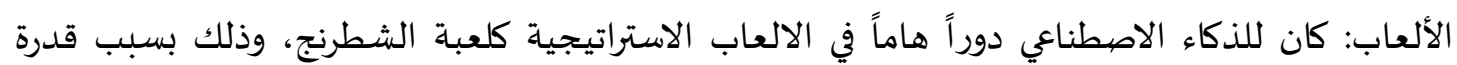

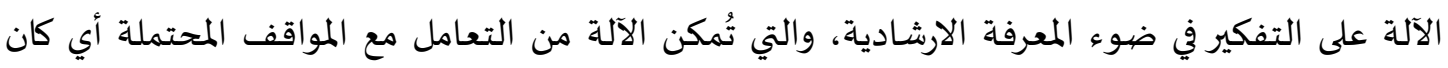
عددها. (- مدا. معالجة اللغة الطبيعية: يمكن للكمبيوتر أن يتفاعل مع الانسان بحسب لغته الطبيعية المنطوقة، فمن خلال الذكاء الاصطناعي يستطيع التمييز بين اللغات المختلفة. مثل برامج الترجمة. النظم الخبيرة: عبارة عن تطبيقات تم تطويرها من أجل حل المشكلات المعقدة بمجال معين، بمستوى

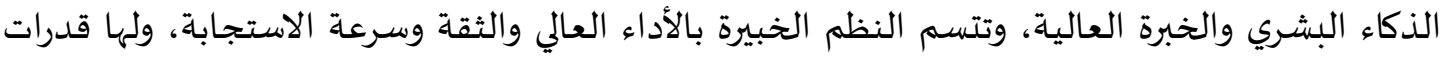

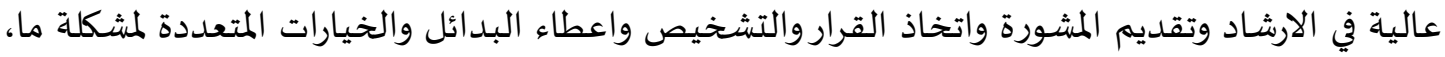
والتنبؤ بالنتائج وتبريرها، وذلك من خلال قواعد المعرفة المتوفرة لديها، مثل انظمة التشخيص الطبي الإلكتروني.

رؤية الكمبيوتر: تقوم هذه التقنية بشكل تلقائي باستخراج المعلومات المفيدة وتحليل وفهم صورة واحدة

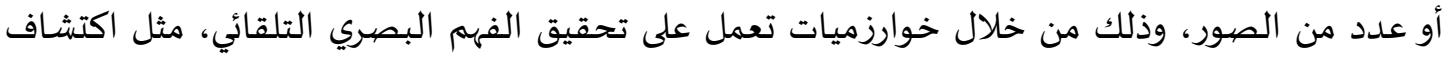

\section{وجاه محدد بين عدد من الصور المختلفة.}

التعرف على الكلام: يمكن للأنظمة الذكية السماع وفهه اللغات بتكوينها ومعانها كالبشر، وتستطيع

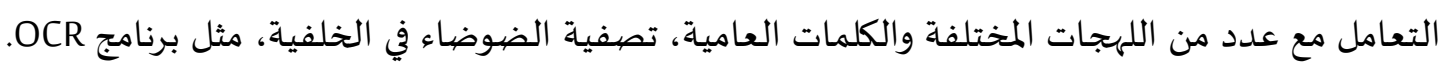
التعرف على خط اليد: يمكنه قراءة النصوص المدونة بخط اليد على الورق أو على شاشة الكمبيوتر

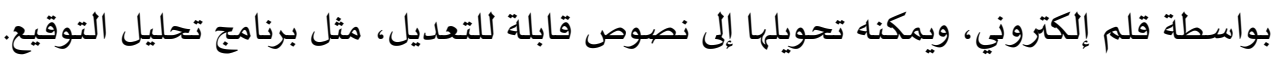

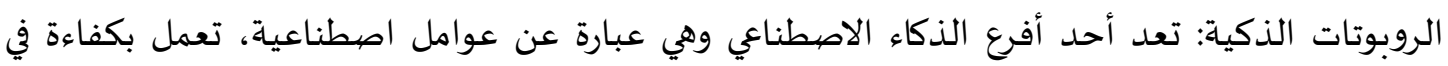

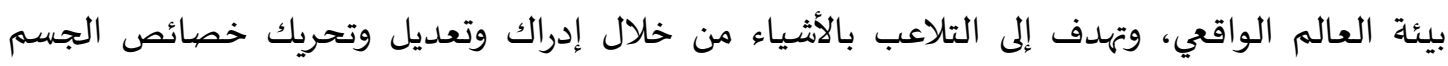

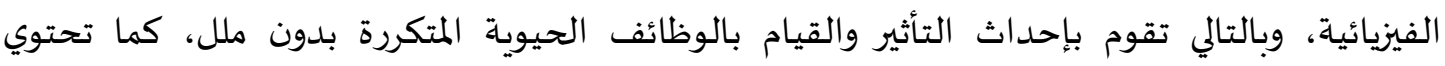

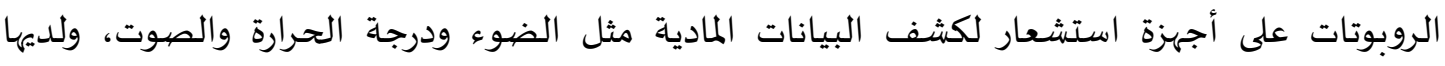

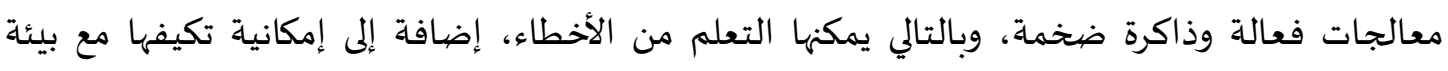

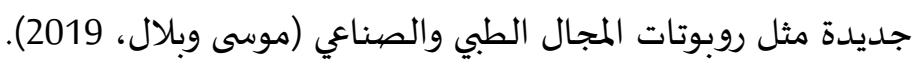

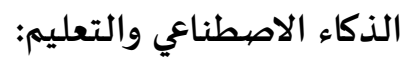

يسعى الذكاء الاصطناعي إلى تحويل العملية التعليمية للأفضل عن طريق إنشاء بيئات تعلم ذكية تجعل العملية التعليمية تتمحور حول الطالب (Mohammed, 2019). إن الذكاء الاصطناعي يؤثر إيجابياً على المراحل

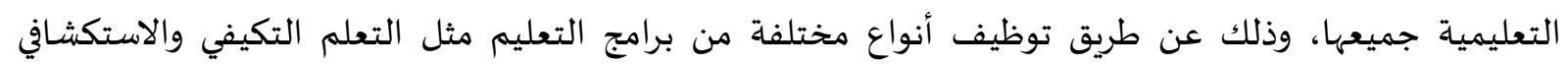

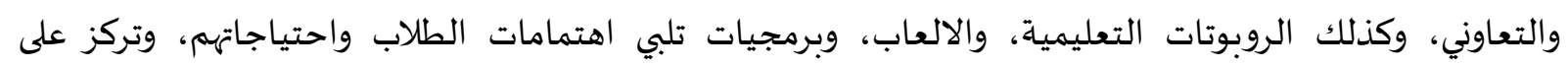


التحديات التي يواجهها الطلاب بأساليب مختلفة، كما أنها تنمي مهارات القرن الحادي والعشرين ومن اهمها مهارات حل المشكلات، ومهارات التفكير الناقد، ومهارات الانتاجية والبرمجة (Mu, 2019). وقد بدأ يسطع مفهوم الذكاء الاصطناعي التربوي (EAI) في هذا الوقت، وهو مجال يتحد فياء كلاً من علوم

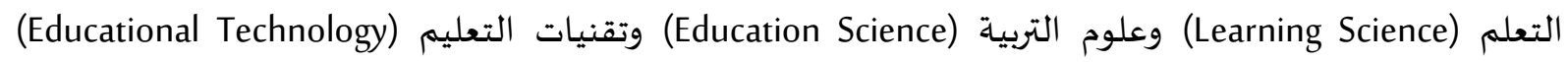
والذكاء الاصطناعي، وذلك بهدف جعل البيئة التعليمية أفضل لتحول الطالب إلى متعلم مشارك ونشط في أي عملية تعليمية عوضاً عن كونه متلقياً سلبياً، كما يقوم بتوفير أدوات تعلم تكيفية ذكية (Mu, 2019). كما يسعى أيضاً إلى إلى

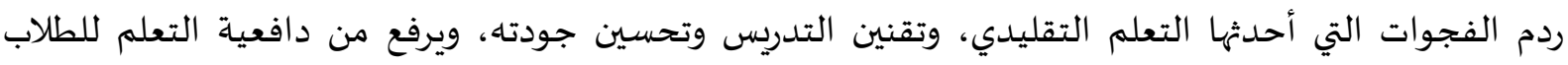
ودافعية التدريس للمعلمين، واكتشاف قدرات المتعلمين، كما يقوم بتحقيق جودة شاملة للتخطيط الوظيفي والتعلم

الفعال (Mu, 2019).

أظهرت دراسة باريت وآخرون ( Barrett et al., 2019 ) فاعلية توظيف تقنيات الذكاء الاصطناعي في التعليم وتأثيرها الإيجابي بتحسين التجربة التعليمية للطلاب. وقد اثبتت دراسة كارالا وآخرون (Karala et al., 2014) فاعلية

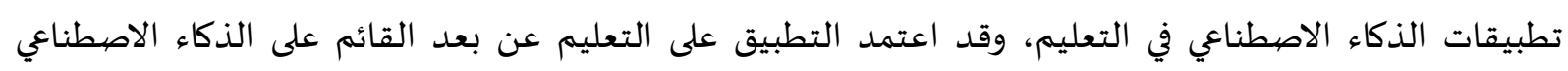
(ARTIMAT) الاتجاه الإيجابي من قبل الطلاب نحو مادة الرياضيات.

\section{معوقات الذكاء الاصطناعي وسلبياته}

أورد العسيري (2019) خمسة معوقات تُعيق المنشآت الحكومية عن تبني الذكاء الاصطناعي وأهمها التالي:

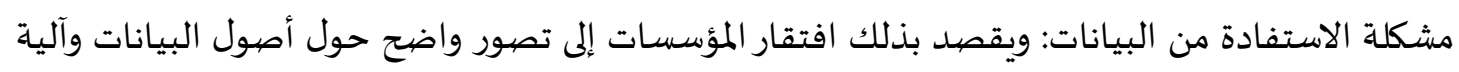

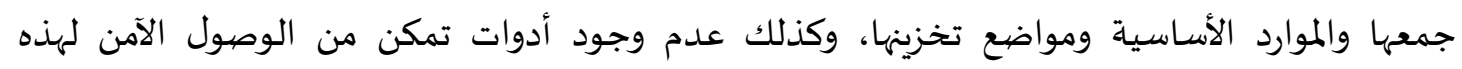
البيانات.

نقص الموارد البشرية المتخصصة في مجال الذكاء الاصطناعي: تعاني عدد من المؤسسات في المجالين العام والخاص من قلة ذوي الاختصاص في مجال الذكاء الاصطناعي والبيانات.

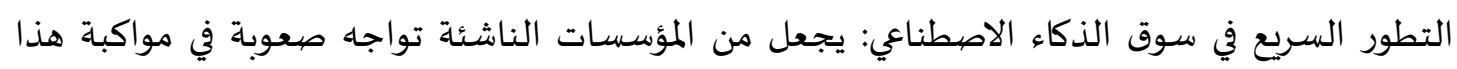

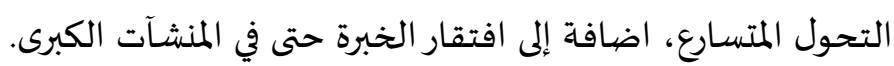

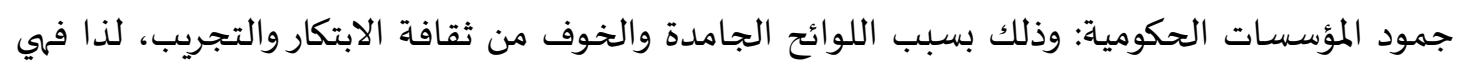
بحاجة إلى المرونة والتحفيز على تحديث أسلوب وطريقة العمل.

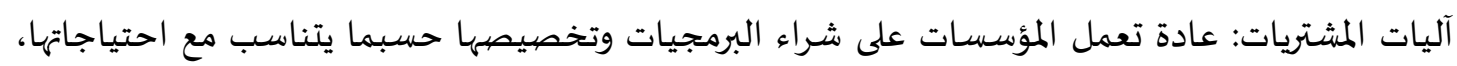

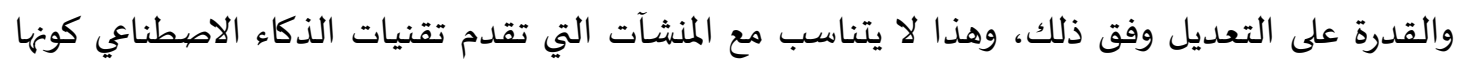
ترفض إطلاع الآخرين على خوارزمياتها (العسيري، 2019).

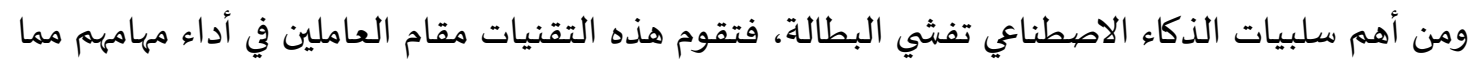

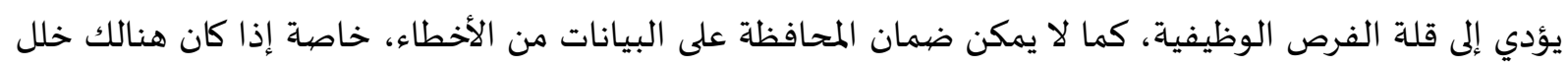

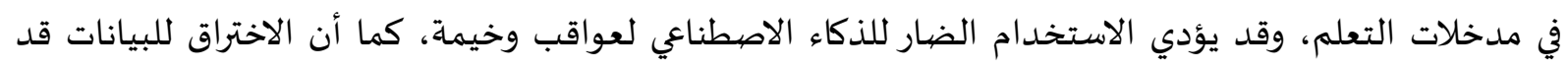
يؤدي إلى أمور سيئة (Taulli, 2019). 
المايكروبت (Microbit)

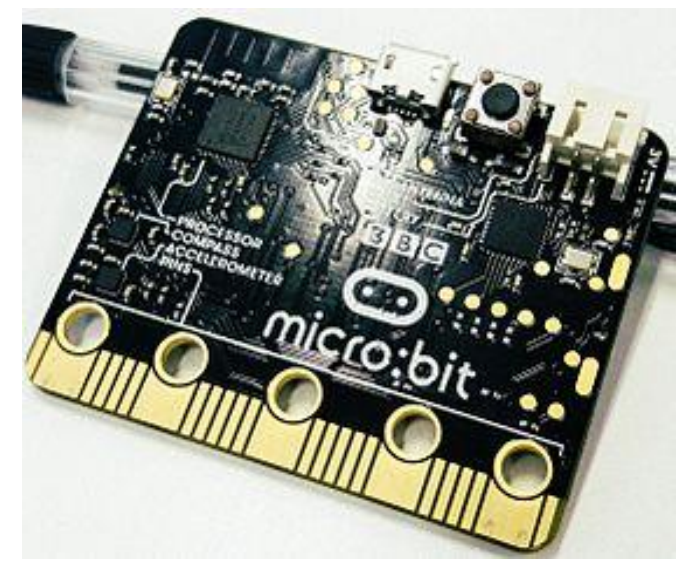

يعرف جهاز المايكروبت (Microbit) بأنه لوح إلكتروني

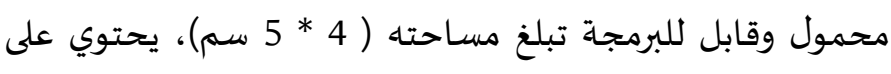

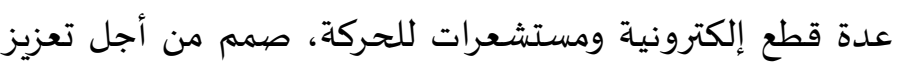
التعلم لدى الطلاب، وتطوير المهارات البرمجية ومهارات التفكير

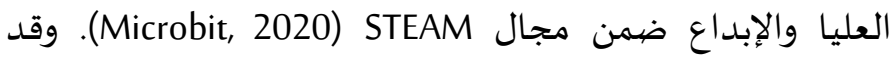
ساهمت هيئة الإذاعة البريطانية BBC في عام (2015 م) في تطوير المايكروبت، بمشاركة ( 29 ) شركة لتصيميم وتصنيع وتوزيع

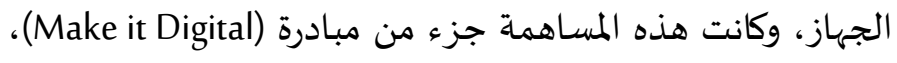
والتي استهدفت محو الأمية الحاسوبية (الظاهري والربيع، 2018).

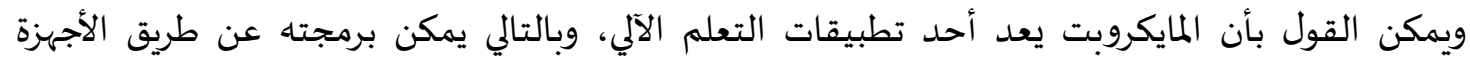
بمختلف أنواعها كأجهزة الحاسب المكتبي والحاسب المتنقل وكذلك الأجهزة اللوحية، كما يتم برمجتها من خلال

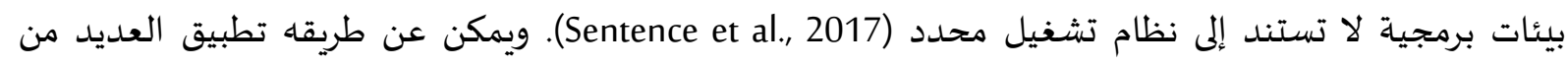

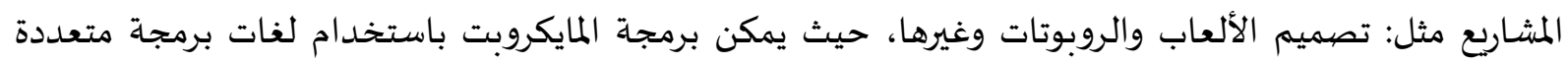

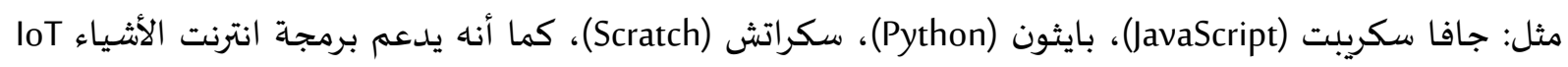
(Sentence et al., 2017)

وقد أظهرت دراسة هودجزوآخرون (Hodges et al., 2017) عدد من النتائج الإيجابية حول تجربة التلاميذ في استخدام المايكروبت (Microbit) وقدرته على تحسين عملية التعلم، فسهولة التعامل مع الجهاز وتعدد (لمدات استخداماته زادت دافعية وحماس الطلاب، وساعدهم على الربط بين تعلم البرمجة وصنع المنتجات الرقمية. 

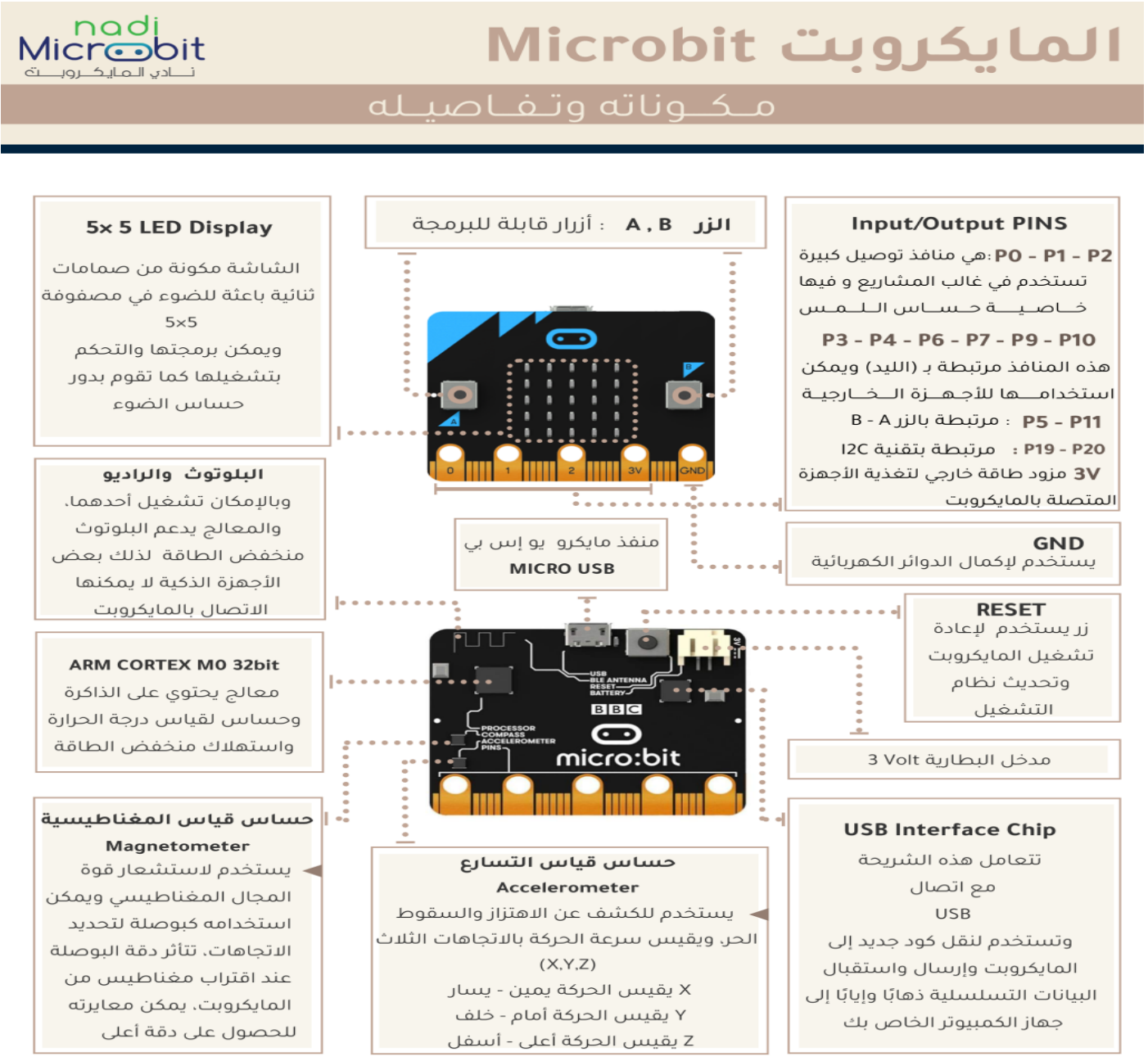

تُعرف البرمجة بأهها "عملية كتابة تعليمات وأوامر للكمبيوتر أو أي جهاز آخر، لتوجيها وإخباره كيفية معالجة

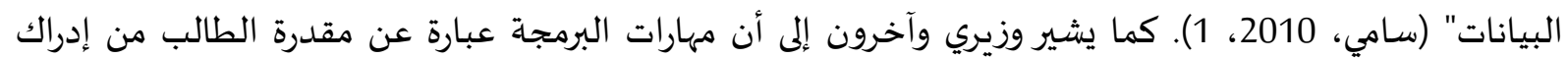
وفهم الأوامر والأكواد وكتابتها بشكل صحيح وباستخدام متقن وبكفاءة عالية تظهر عند تطبيق وتشغيل البرنامج

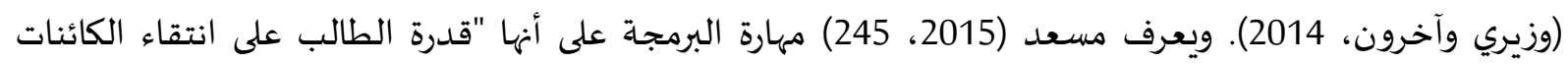

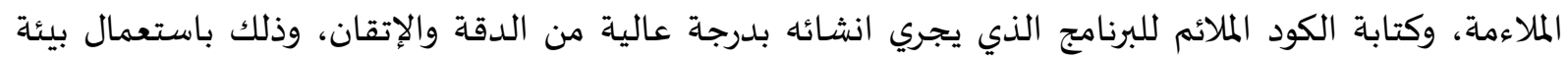
تطوير متكاملة". في هذه الدراسة تعرف البرمجة بأنها مجموعة أوامر وتعليمات يتم كتابتها من أجل تنفيذ برنامج معين،

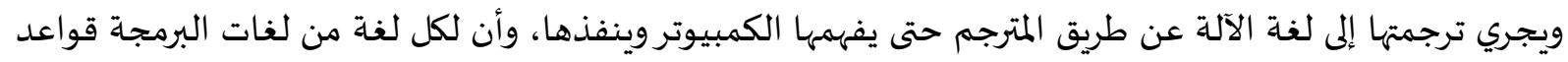

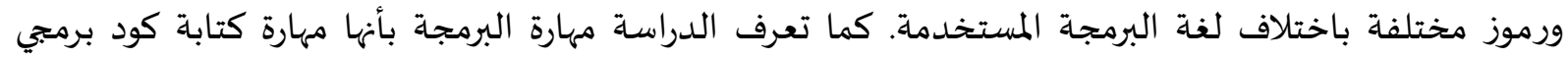

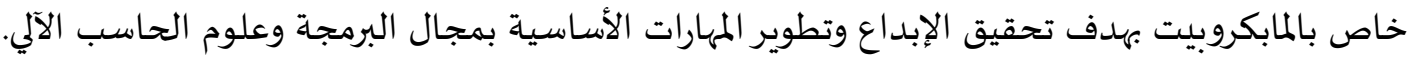




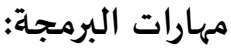

مهارات البرمجة مشتركة بين جميع لغات البرمجة هي: (مهارة التخطيط للبرنامج، مهارة كتابة الخوارزميات،

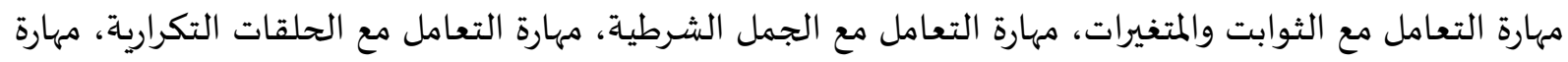

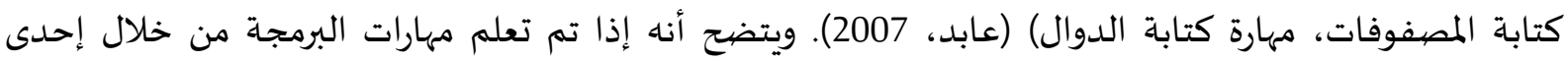

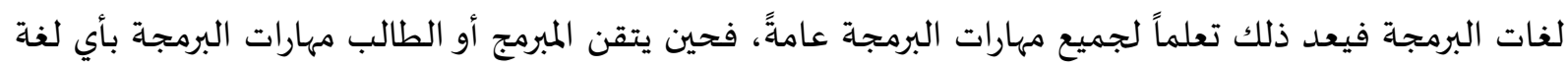

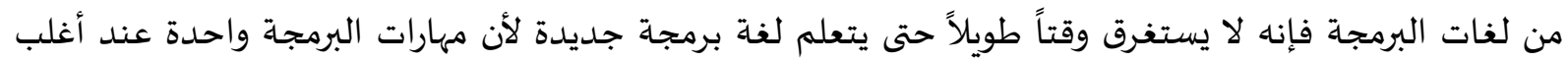
لغات البرمجة (الخليفة، 2005).

سعت دراسة شريف المرسى (المرسى، 2011) إلى تنمية مهارات البرمجة لدى طلاب كلية التربية النوعية

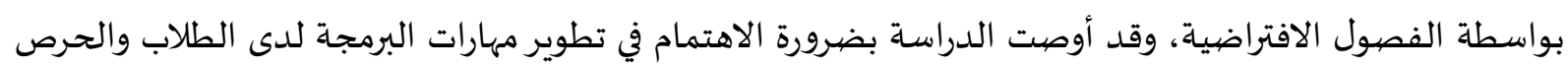
على تدريههم لمعالجة القصور فيها. وهدفت دراسة وهبي وآخرون (Ouahbi et al., 2015) لتعلم مفاهيم البرمجة الأساسية عن طريق إنشاء الألعاب لطلاب الصف الأول ثانوي، وذلك للتغلب على المشاكل البرمجية والتي تركزت في أساسيات بناء الجملة

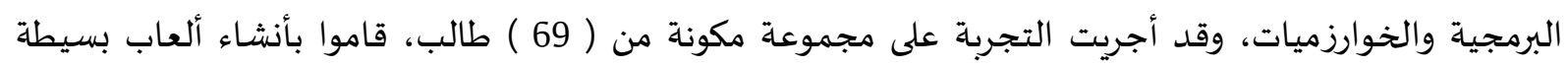

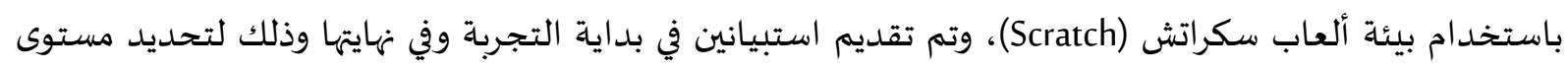

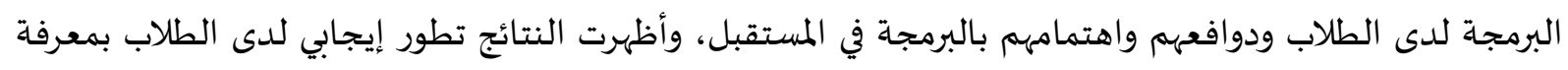
أعمق لمفاهيم البرمجة ورفع مستوى أدائهم بكفاءة، ورفعت من دافعيتهم حيث أبدى بعض المض الطلاب اهتمامهيم

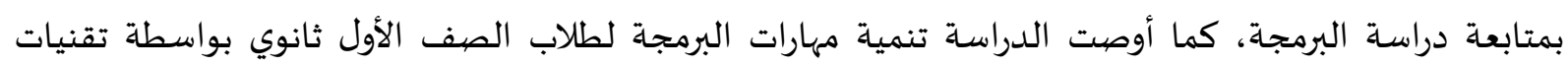
أخرى يمكن أن تحفز الطلاب لتعلم البرمجة أكثر.

أهداف تعلم البرمجة باستخدام المايكروبت إن لتعلم البرمجاة باستخدام المايكروبت الكثير من الأهداف ويطول الحديثلثيث عنها وسيتم إيجازها كما يلي:

$$
\begin{aligned}
& \text { 1. تثقيف المجتمع بأهمية التقنية. } \\
& \text { 2. تشجيع الطلاب على الابتكار. } \\
& \text { 3. اعتبار التقنية جزء من نشاط التعلم. } \\
& \text { 4. توجياء الطلاب إلى ضرورة البحث والاطلاع على جديد المبار الموارد التقنية. } \\
& \text { 5. تخصيص بعض البرمجيات لحل المشكلات وتوظيف التفكير الناقد. } \\
& \text { 6. تشجيع الطلاب على إنتاج مشاريع تقنية خاصة بهيهم. }
\end{aligned}
$$

ثانياً - الدراسـات السابقة:

- - هدفت دراسة جوميز وآخرون (Gomes et al. 2018) إلى استكشاف مستويات الدافعية لدى الطلاب وربطها

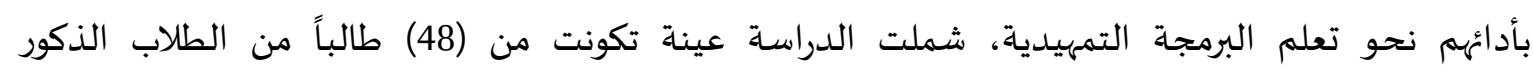
المتخصصين في بكالوريوس علوم الحاسوب، وبينت النتائج وجود علاقة إيجابية وارتباط بين أداء الطلاب نحونة

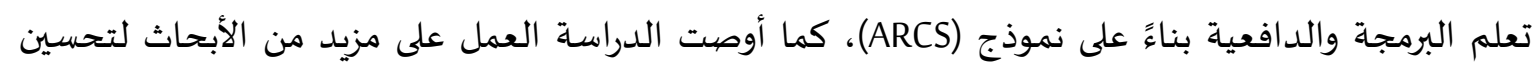

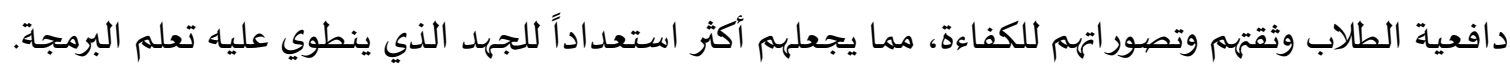

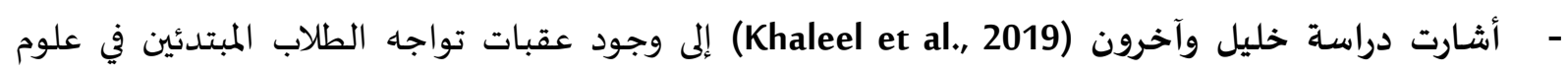

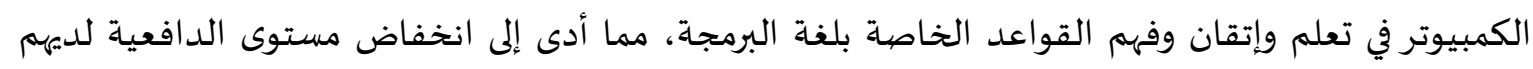


نحو تعلم البرمجة، فهدفت الدراسة إلى قياس مستوى الدافعية لتعلم مفاهيم البرمجة من خلال موقع تعليمي

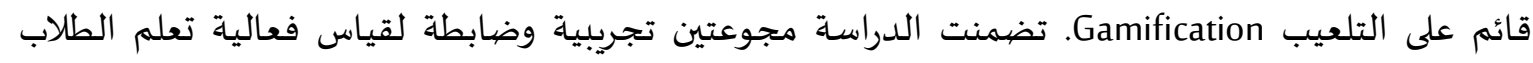
مفاهيم لغة البرمجة، بالإضافة إلى تقييم دافعية الطلاب باستخدام نموذج الدافعية (ARCS) الذي يشمل

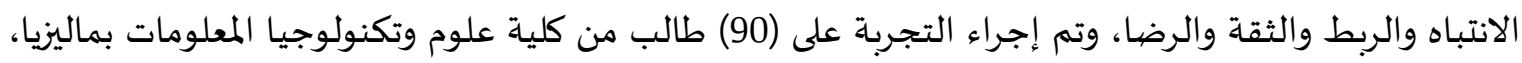

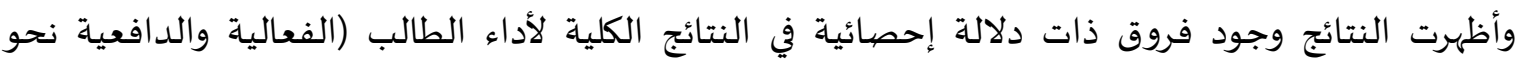

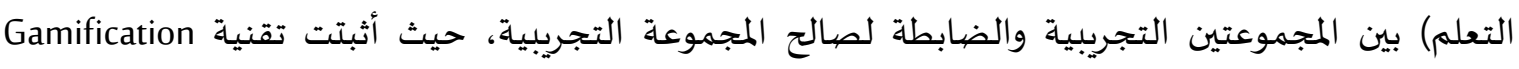

فاعليتها في حل مشاكل تعلم لغة البرمجة وزيادة أداء الطلاب ورفع دافعيتهم (Khaleel et al., 2019).

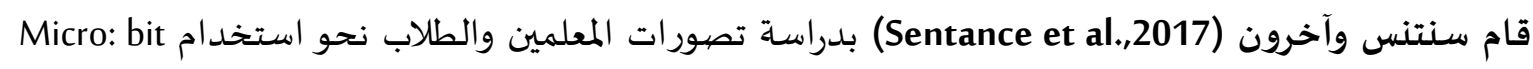

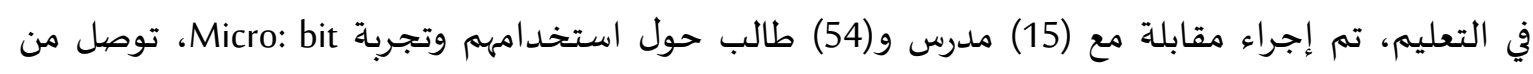

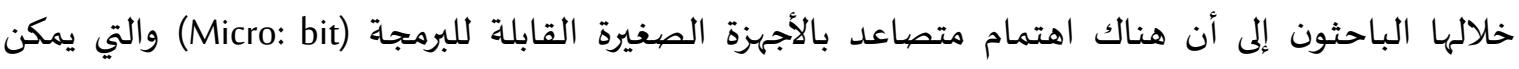

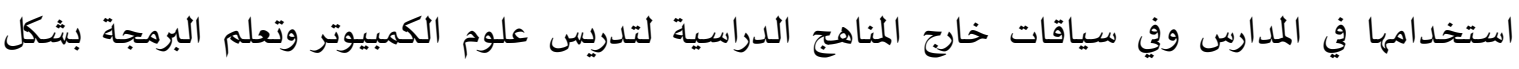
ميسر، وخوض تجربة حوسبة فعلية عن طريق عن تصميم كائنات وأنظمة تفاعلية ملموسة بطريقة المبات مبتكرة.

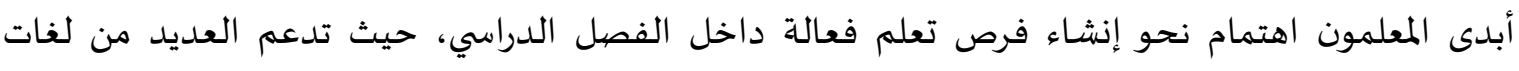

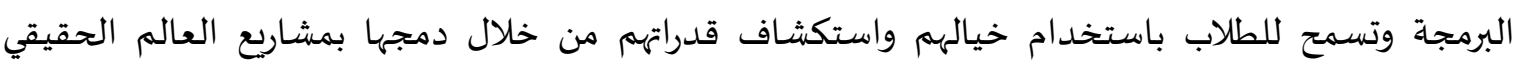
.(Sentance et al.,2017)

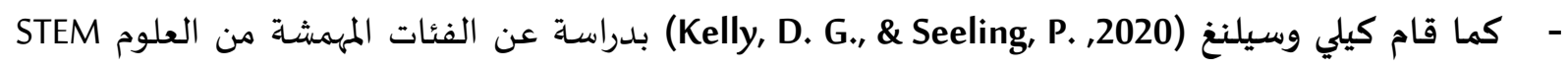

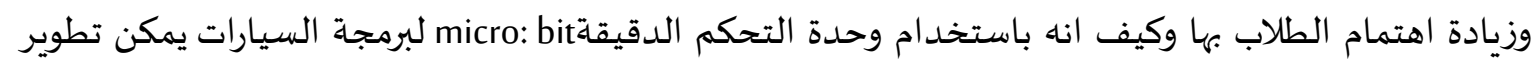

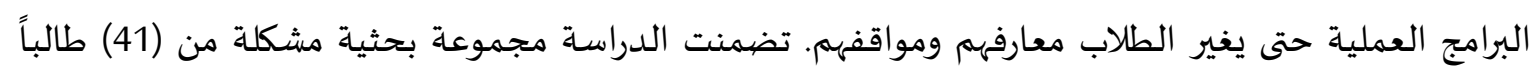

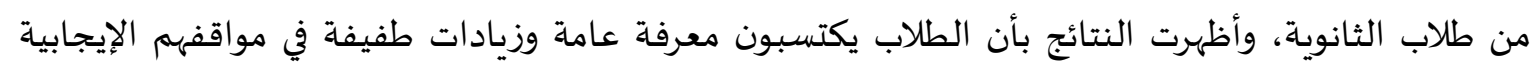

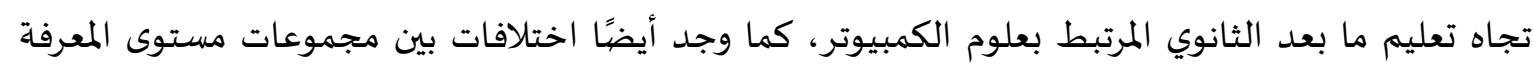
الواردة وإدراك الذات بالإضافة إلى اختلافات في الأداء (Kelly, D. G., \& Seeling, P. 2020).

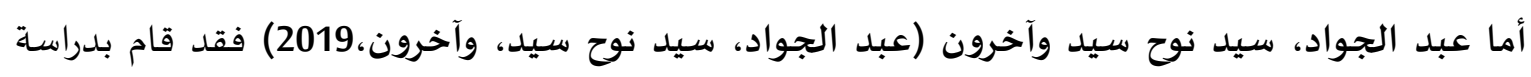

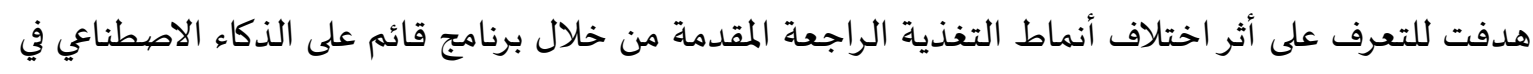

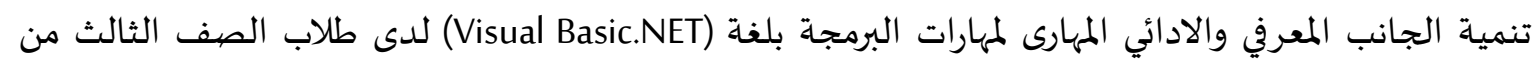

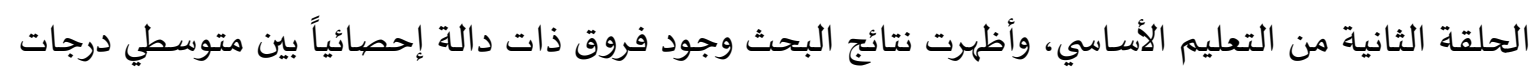

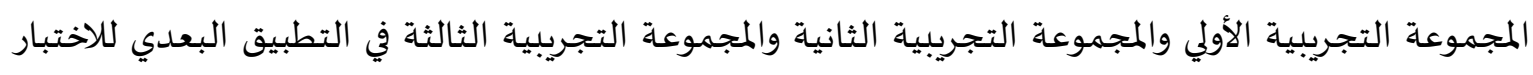

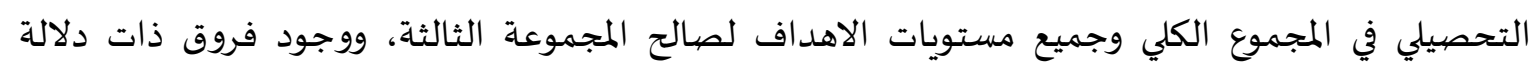

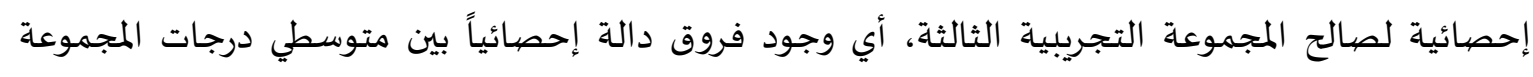

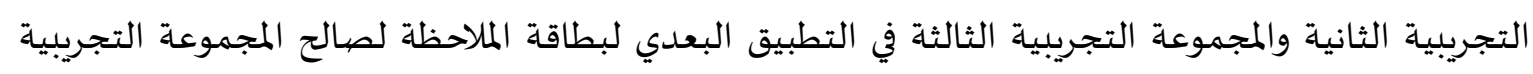
الثالثة(عبد الجواد، سيد نوح سيد، وآخرون،2019).

تعليق على الدراسات السـابقة:

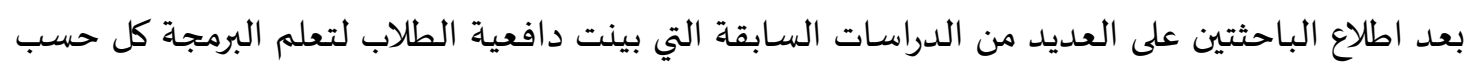

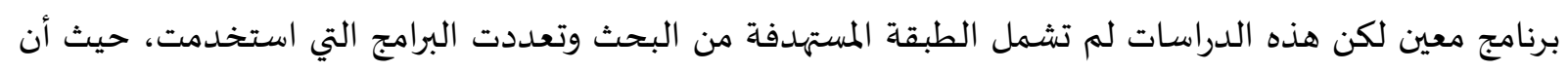


الدراسات السابقة لم تستخدم الذكاء الاصطناعي المايكروبت كنقطة أساسية في زيادة الدافعية نحو تعلم البرمجة بشكل خاص.

3- منهجية البحث وإجراءاته.

منهجية البحث:

يتبع البحث المنهج شبه التجريبي ذو المجموعة التجريبية الواحدة، والذي يسعى لتوضيح أثر المتغير المستقل وهو الذكاء الاصطناعي (Microbit) على المتغير التابع وهو الدافعية نحو تعلم البرمجة.

مجتمع البحث وعينته: يتبع تحديد العينة طريقة الحصر الشامل لمجتمع البحث وهن طالبات ماجستير تقنيات التعليم (مشروع

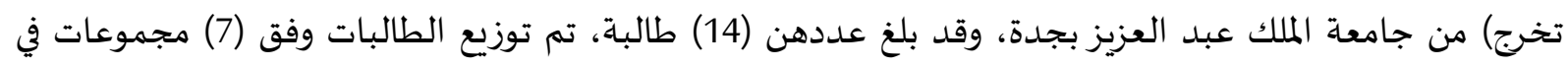

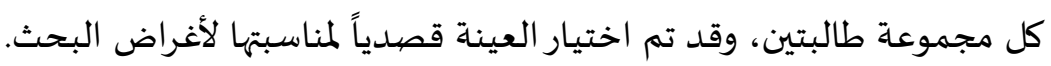

أدوات البحث:

تم جمع البيانات عن طريق مقياس قبلي وبعدي لقياس دافعية الطالبات نحو تعلم البرمجة سعياً لتحقيق

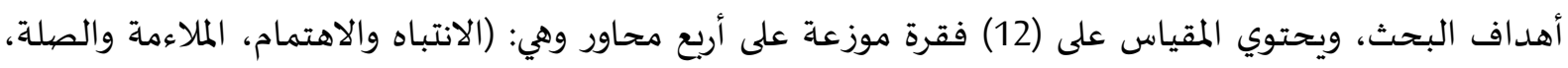

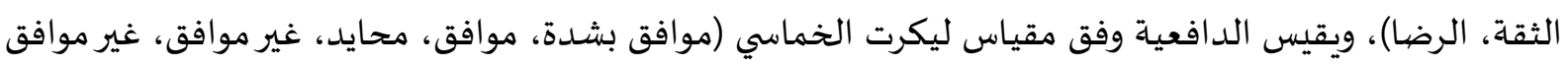

بشدة).

صددق المقياس: تم عرض المقياس القبلي والبعدي على مجموعة محكمين متخصصين في مجال تقنيات التعليم، وذلك

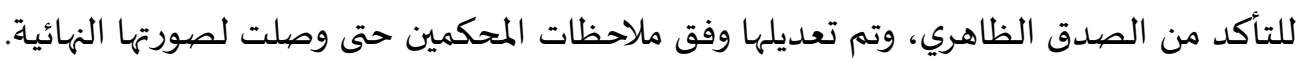

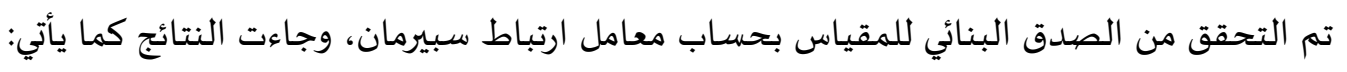

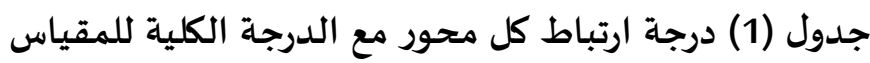

\begin{tabular}{|c|c|c|}
\hline معامل الآتباط & المحور & الرقم \\
\hline $0.880^{* *}$ & الانتباه والاهتمام & 1 \\
\hline $0.910^{* *}$ & الملاءمة والصلة & 2 \\
\hline $0.702^{* *}$ & الثقة & 3 \\
\hline $0.865^{* *}$ & الرضا & 4 \\
\hline
\end{tabular}

يتبين من الجدول (1)، أن قيم معاملات الارتباط بين درجة كل محور والدرجة الكلية لمقياس الدافعية نحو

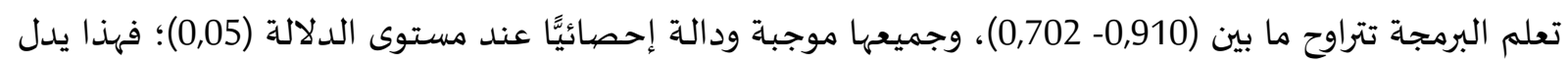
على اتساق داخلي عالي، مما يعكس صدقاً عالياً لفقرات المقياس. 
ثبات المقياس

تم حساب معامل ألفا كرونباخ للتحقق من ثبات المقياس، كما يوضح جدول (2) أن معاملات الثبات لمحاور

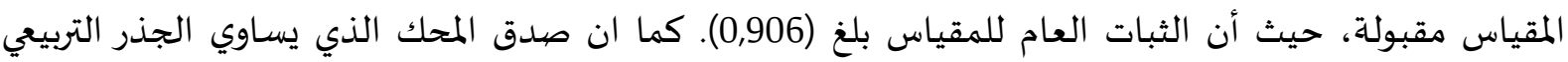

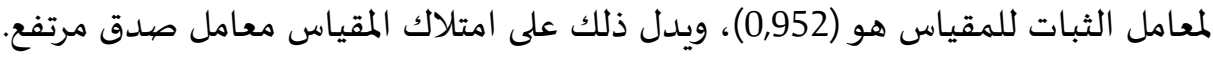

جدول (2): الصدق والثبات لمقياس الدافعية نحو تعلم البرمجة

\begin{tabular}{|c|c|c|c|c|}
\hline الصيدق & الثبات & عدد الفقرات & المحور & الرقم \\
\hline 0.918 & 0.843 & 3 & الانتباه والاهتمام & 1 \\
\hline 0.789 & 0.624 & 4 & الملاءمة والصلة & 2 \\
\hline 0.925 & 0.855 & 3 & الثقة & 3 \\
\hline 0.748 & 0.559 & 2 & الرضا & 4 \\
\hline 0.952 & 0.906 & 12 & \multicolumn{2}{|c|}{ إجمالي المقياس } \\
\hline
\end{tabular}

\section{الأساليب الإحصيائية}

للتحقق من أدوات البحث تم استخدام معامل ألفا كرونباخ لحساب الثبات، ومعامل ارتباط سبيرمان

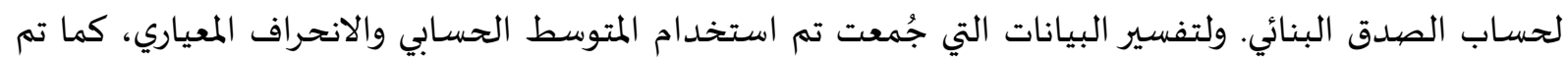
تطبيق اختبار ولكوكسون (Wilcoxon Test) للعينات المترابطة، لأن حجم العينة أقل من (30)، ولا تتبع التوزيع الطبيعي، فالاختبارات اللامعلمية هي الأنسب.

المواد التجبريبية:

لتحقيق أهداف البحث تم تقديم ورشـة تدربية وذلك عن طريق نظام الفصول الافتراضية Blackboard (Collaborate Ultra)

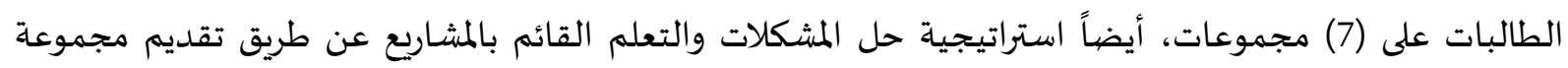
أنشطة متنوعة تعرض مشكلة ويتم حلها عن طريق بناء كود برمجي باستخدام المايكروبت، وذلك لرفع دافعية

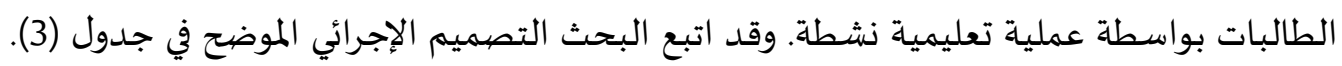

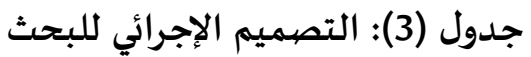

\begin{tabular}{|c|c|c|}
\hline المقياس البعدي & المعالجة التجريبية & المقياس القبلي \\
\hline مقياس IMMS لقياس الدافعية & 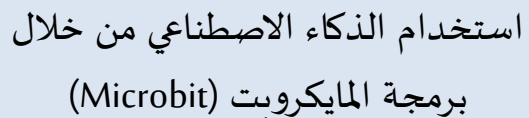 & مقياس IMMS لقياس الدافعية \\
\hline
\end{tabular}

خطوات تطبيق التجربة

توزيع الطالبات الى (7) مجموعات كل مجموعة تحتوي على طالبتين.

استخدام مقياس IMMS لقياس الدافعية نحو تعلم البرمجة كمقياس قبلي.

تقديم ورشـة تدريبية وذلك عن طريق نظام الفصول الافتراضية (Blackboard Collaborate Ultra). تقديم مجموعة أنشطة متنوعة تعرض مشكلة ويتم حلها عن طريق بناء كود برمجي باستخدام المايكروبت. بعد انتهاء الورشـة التدريبة تم استخدام مقياس IMMS لقياس الدافعية نحو تعلم البرمجة. 
4- عرض النتائج ومناقشتها. الإجابة عن سؤال البحث: "ما أثر الذكاء الاصطناعي المايكروبت (Microbit) في رفع الدافعية نحو تعلُّم البرمجة

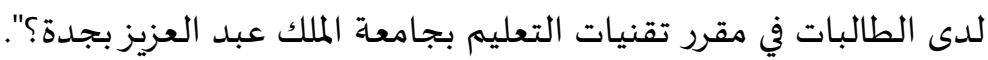

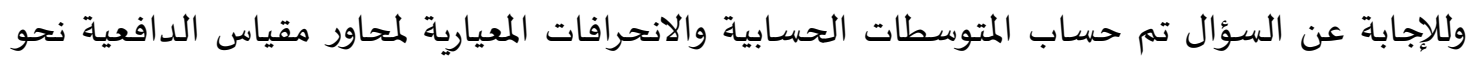

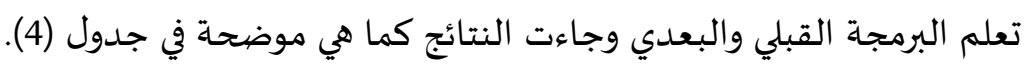

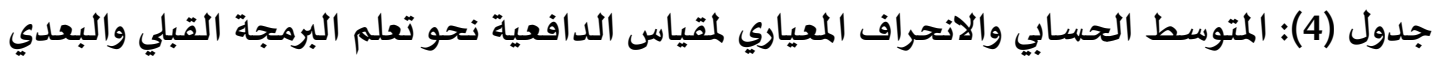

\begin{tabular}{|c|c|c|c|c|}
\hline \multicolumn{2}{|c|}{ المقياس البعدي } & \multicolumn{2}{|c|}{ المقياس القبلي } & \multirow{2}{*}{ المحاور } \\
\hline الانحراف المعياري & المتوسط الحسابي & الانحراف المعياري & المتوسط الحسابي & \\
\hline 0.141 & 4.93 & 0.702 & 1.95 & الانتباه والاهتمام \\
\hline 0.402 & 4.71 & 0.443 & 1.77 & الملاءمة والصلة \\
\hline 0.251 & 4.86 & 0.712 & 1.81 & الثقة \\
\hline 0.305 & 4.86 & 0.560 & 1.61 & 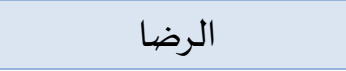 \\
\hline 0.209 & 4.84 & 0.520 & 1.78 & المتوسط العام للمقياس \\
\hline
\end{tabular}

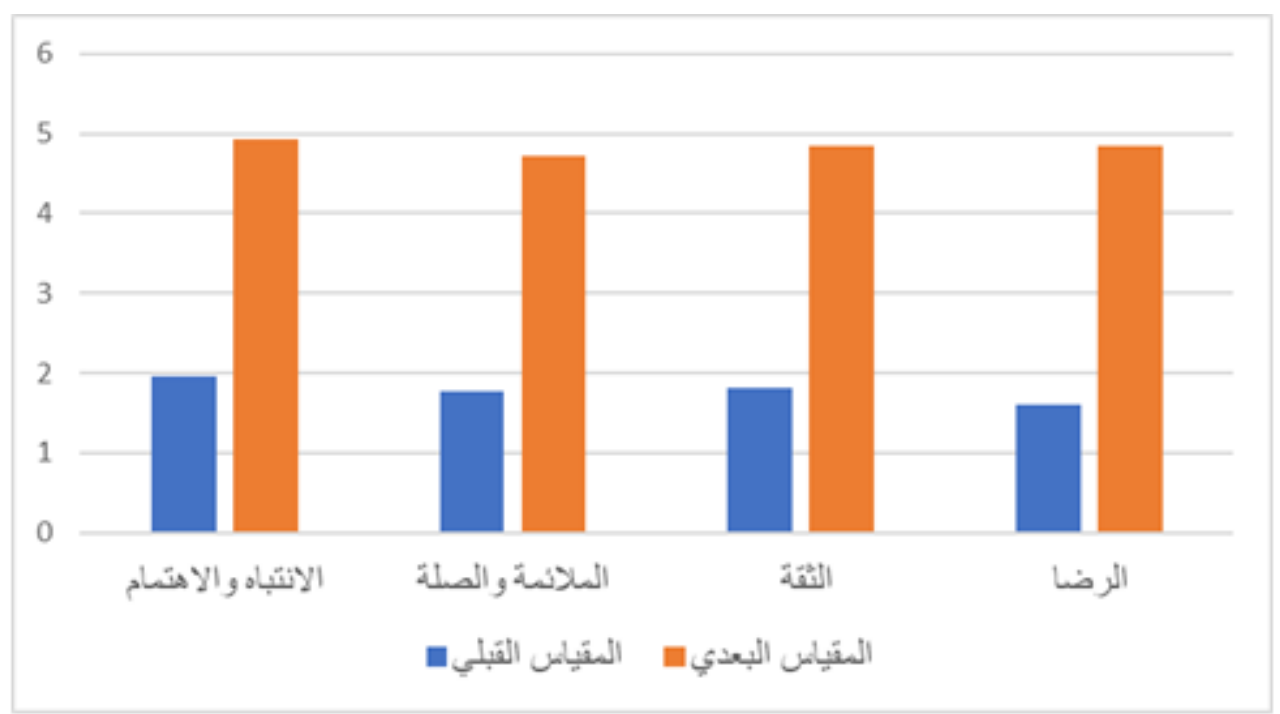

شكل (2) قيمة المتوسط الحسابي لمحاور مقياس الدافعية نحو تعلم البرمجة

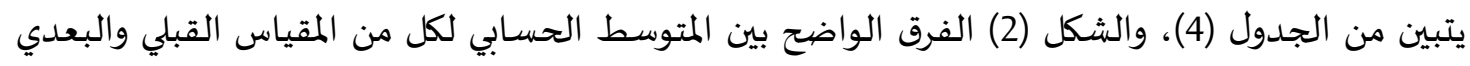

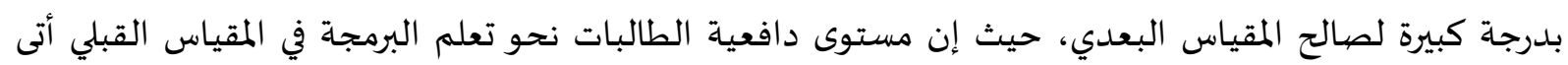

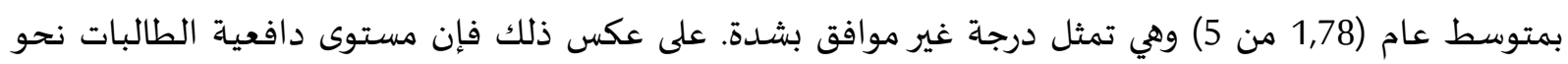

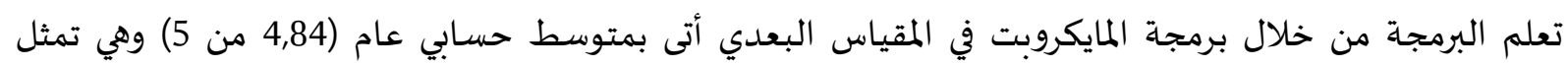

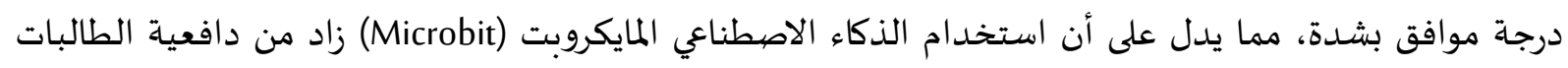

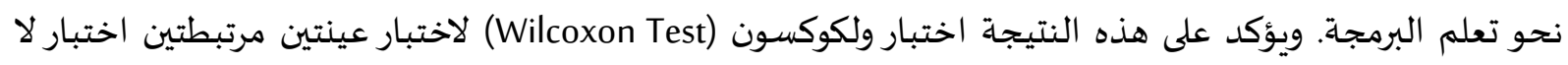

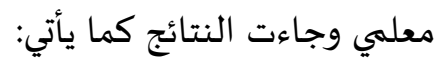


جدول (5): الرتب لاختبار ولكوكسون قبل وبعد اجراء التطبيق

\begin{tabular}{|c|c|c|c|c|}
\hline & & $\mathbf{N}$ & Mean Rank & Sum of Ranks \\
\hline \multirow{4}{*}{ After-Before } & Negative Ranks & $0^{a}$ & 0 & 275.00 \\
\hline & Positive Ranks & $14^{b}$ & 14.56 & 131.00 \\
\hline & Ties & $0^{c}$ & & \\
\hline & Total & 14 & & \\
\hline \multicolumn{5}{|c|}{ وقد تم تطبيق الاختبار Zوكانت النتائج كما يلي: } \\
\hline \multicolumn{5}{|c|}{ After - Before } \\
\hline \multicolumn{2}{|c|}{ Z } & \multicolumn{2}{|r|}{$6.640-^{\mathrm{a}}$} & \\
\hline \multicolumn{2}{|c|}{ Asymp. Sig. (2-tailed) } & \multicolumn{2}{|r|}{0.00} & \\
\hline
\end{tabular}

ومن هنا يتبين أن هنالك فروق ذات دلالة إحصائية بين نتائج الطالبات لدافعيتهن نحو تعلم البرمجة قبل

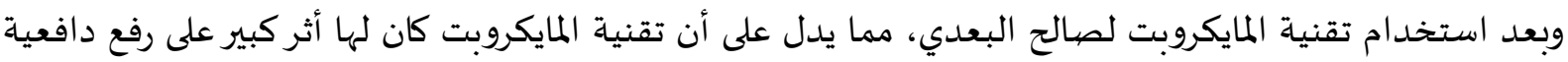

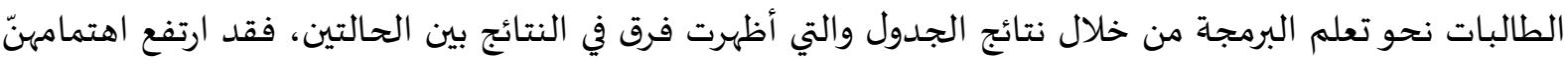

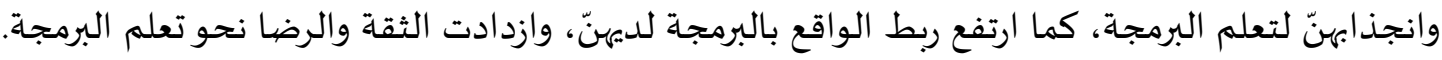

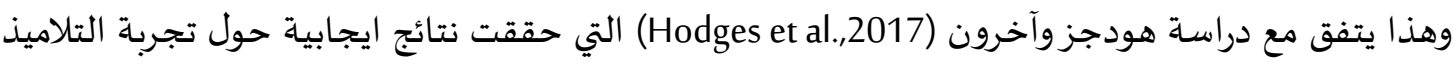

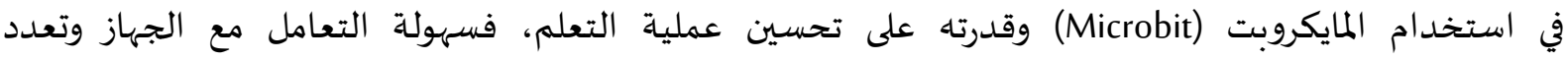

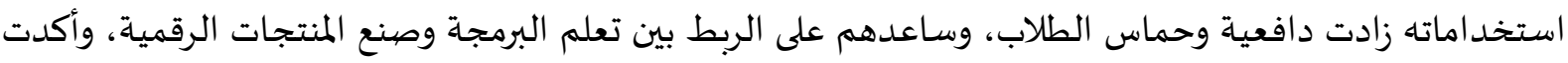
على ذلك دراسة باريت وآخرون (Barrett et al., 2019) حيث أثبتت فاعلية دمج الذكاء الاصطناعي في التعليم وتأثيره

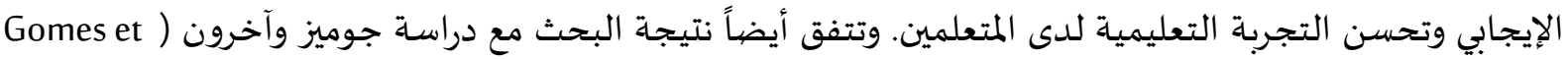

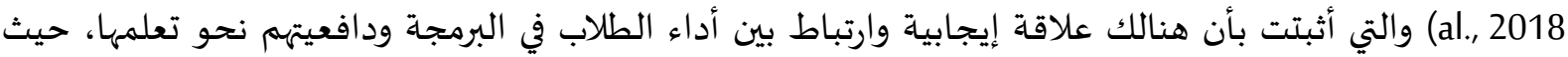

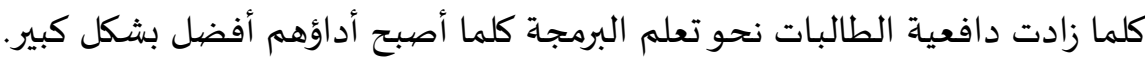

\section{التوصيات والمقترحات.}

1- الحرص على رفع الدافعية نحو التعلم لدى الطلاب، لما لها من أثر تربوي عميق لتعلمهم وانخراطهم، عن طريق تقنيات التعليم المتعددة لاسيما تقنيات الذكاء الاصنطاء لاصناعي. 2- العمل على دمج تقنيات الذكاء الاصطناعي في المناهج والمشاريع الدراسية لدورها الفياتيات الفعال في جعل التعليم عملية نشطة.

3- تهيئة المؤسسات التعليمية وتدريب المعلمين على استخدام تقنيات الذكاء الاصطناعي المختلفة، لكي يصبحوا قادرين على تعليم الطلاب بإتقان ودقة. 4- توفير أجهزة مايكروبت في المدارس والجامعات لدورها الفعال في حل مشاكل تعلم لغة البرمجة وزيادة أداء الطلاب ورفع دافعيتهم. 5- تعزيز الدافعية لدى الطلاب نحو التعلم من خلال إنتاج مشاريع ضمن مجال STEAM باستخدام المايكروبت.

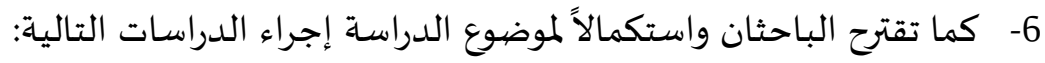

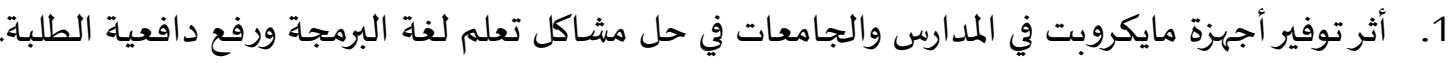


2. فاعلية تهيئة المؤسسات التعليمية وتدريب المعلمين على استخدام تقنيات الذكاء الاصطناعي المختلفة.

- - مأبو غزال، معاوية وآخرون (2013) علم النفس التربوي التطبيق والنظرية. (ط3). عمّان، الأردن: دار المسيرة

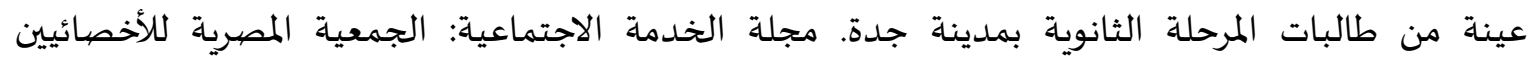

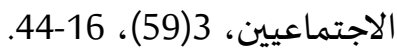

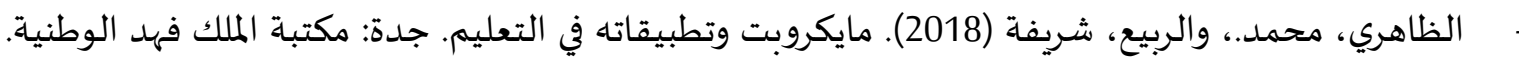

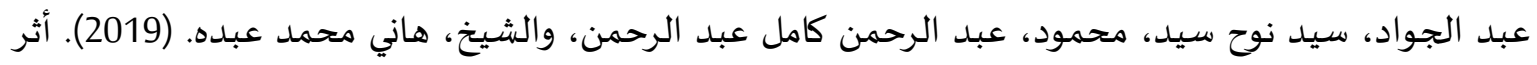

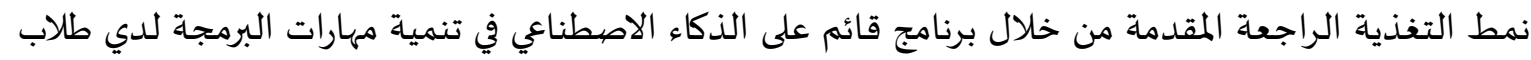

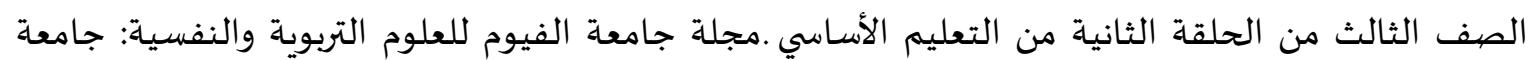
الفيوم- كلية التربية، عن 12، ج4، 1779-219.

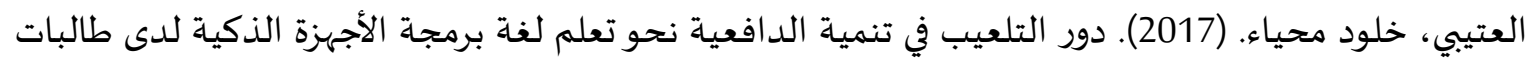

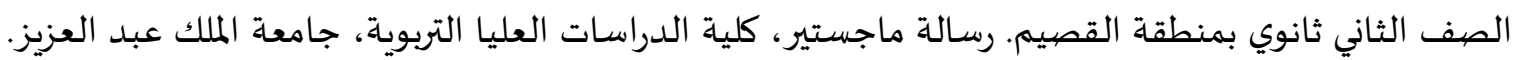

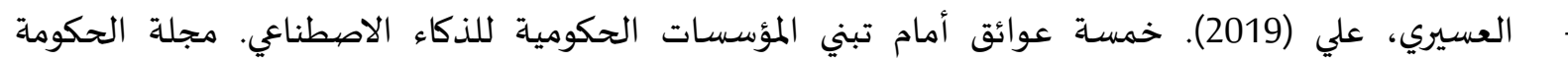

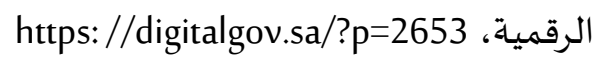
موسى، عبد الله وبلال، أحمد حبيب (2019). الذكاء الاصطناعي ثورة في تقنيات التعليم. القاهرة: المجموعة العربية للتدريب والنشر.

ثانياً- المراجع بالإنجليزية:

- Al Bado, A. M. A. (2017). The Impact of Laboratory Teaching, Using the Educational Robot in the Development of Mathematical Achievement for Sci-12th grade students in Amman-Jordan schools. The International Journal for Talent Development, 8, 133-152.

- Barrett, M., Branson, L., Carter, S., DeLeon, F., Ellis, J., Gundlach, C., \& Lee, D. (2019). Using Artificial Intelligence to Enhance Educational Opportunities and Student Services in Higher Education. Inquiry: The Journal of the Virginia Community Colleges, 22(1), 11.

- Gomes, A., Ke, W., Lam, C. T., Marcelino, M. J., \& Mendes, A. (2018, October). Student motivation towards learning to program. In 2018 IEEE Frontiers in Education Conference (FIE) (pp. 1-8). IEEE.

- Gottfried, A. E. (1990). Academic Intrinsic Motivation in Young Elementary School. Journal of Educational Psychology, 82(3), 525. 
- Hodges, S., Sentance, S., Waite, J., MacLeod, E., \& Yeomans, L. (2017). Creating Cool Stuff: Pupils' Experience of the BBC micro: bit. In Proceedings of the 2017 ACM SIGCSE Technical Symposium on Computer Science Education (pp. 531-536). ACM.

- Jawawi, D. N., Mamat, R., Ridzuan, F., Khatibsyarbini, M., \& Zaki, M. Z. M. (2015, May). Introducing computer programming to secondary school students using mobile robots. In 2015 10th Asian Control Conference (ASCC) (pp. 1-6). IEEE.

- Jenkins, T. (2001, June). The motivation of students of programming. In Proceedings of the 6th annual conference on Innovation and technology in computer science education (pp. 53-56).

- Karal, H., Nabiyev, V., Erümit, A. K., Arslan, S., \& Çebi, A. (2014). Students' opinions on Artificial Intelligence based Distance Education System (Artimat). Procedia-Social and Behavioral Sciences, $136,549-553$.

- Kelly, D. G., \& Seeling, P. (2020). Introducing underrepresented high school students to software engineering: Using the micro: bit microcontroller to program connected autonomous cars. Computer Applications in Engineering Education, 28(3), 737-747.

- $\quad$ Khaleel, F. L., Ashaari, N. S., \& Wook, T. S. M. T. (2019). An empirical study on gamification for learning programming language website. Jurnal Teknologi, 81(2), 151-162.

- McClelland, C. (2017). The Difference between artificial intelligence, machine learning, and deep learning. Retrieved February, 13, 2018.

- Microbit. (2020). Access date, March 13, 2020. https://microbit.org/

- Mohammed, P. S. (2019). Towards Inclusive Education in the Age of Artificial Intelligence: Perspectives, Challenges, and Opportunities. In Artificial Intelligence and Inclusive Education (pp. 1737). Springer, Singapore.

- Mu, P. (2019, September). Research on artificial intelligence education and its value orientation. In 1st International Education Technology and Research Conference (IETRC 2019), China, Retrieved from https: //webofproceedings. org/proceedings_series/ESSP/IETRC (Vol. 202019).

- OxfordDictionary. (2020) Artificial Intelligence, Access date, March 13, 2020. https: //www.oed.com/

- Sentance, S., Waite, J., Yeomans, L., \& MacLeod, E. (2017, November). Teaching with physical computing devices: the BBC micro: bit initiative. In Proceedings of the 12th Workshop on Primary and Secondary Computing Education (pp. 87-96). ACM.

- Southgate, E., Blackmore, K., Pieschl, S., Grimes, S., McGuire, J., \& Smithers, K. (2019). Artificial Intelligence and Emerging Technologies in Schools. URL: apo.org.au/node/254301

- Taulli, T. (2019). The Future of Al. In Artificial Intelligence Basics (pp. 161-176). Apress, Berkeley, CA.

- Topalli, D., \& Cagiltay, N. E. (2018). Improving Programming Skills in Engineering Education Through Problem-based Game Projects with Scratch. Computers \& Education, 120, 64-74. 